\title{
Micro-nanostructural designs of bifunctional electrocatalysts for metal-air batteries
}

\author{
Fang Shi a,b, Xuefeng Zhu ${ }^{a, *}$, Weishen Yang a \\ a State Key Laboratory of Catalysis, Dalian Institute of Chemical Physics the Chinese Academy, Dalian 116023, Liaoning, China \\ ${ }^{\mathrm{b}}$ University of Chinese Academy of Sciences, Beijing 100049, China
}

\section{A R T I C L E I N F O}

\section{Article history:}

Received 24 July 2019

Accepted 23 September 2019

Published 5 March 2020

\section{Keywords:}

Oxygen reduction reaction

Oxygen evolution reaction

Rechargeable metal-air batteries

Bifunctional electrocatalysts

Micro-nano structure

\begin{abstract}
A B S T R A C T
Water-based rechargeable metal-air batteries play an important role in the storage and conversion of renewable electric energy. However, the sluggish kinetics of the oxygen reduction reaction (ORR) and oxygen evolution reaction (OER) have limited the practical application of rechargeable metal-air batteries. Most of reviews were focused on single functional electrocatalysts while few on bifunctional electrocatalysts. It is indispensable but challenging to design a bifunctional electrocatalyst that is active and stable to the two reactions. Recently, attempts to develop high active bifunctional electrocatalysts for both ORR and OER increase rapidly. Much work is focused on the micro-nano design of advanced structures to improve the performance of bifunctional electrocatalyst. Transition-metal materials, carbon materials and composite materials, and the methods developed to prepare micro-nano structures, such as electrochemical methods, chemical vapor deposition, hydrothermal methods and template methods are reported in literatures. Additionally, many strategies, such as adjustments of electronic structures, oxygen defects, metal-oxygen bonds, interfacial strain, nano composites, heteroatom doping etc., have been used extensively to design bifunctional electrocatalysts. To well understand the achievements in the recent literatures, this review focuses on the micro-nano structural design of materials, and the related methods and strategies are classed into two groups for the improvement of intrinsic and apparent activities. The fine adjustment of nano structures and an in-depth understanding of the reaction mechanism are also discussed briefly.
\end{abstract}

(C) 2020, Dalian Institute of Chemical Physics, Chinese Academy of Sciences. Published by Elsevier B.V. All rights reserved.

\section{Introduction}

Energy is an important foundation and a safeguard for the development of economics and society. The utilization of electric energy has prompted the rapid development of human civilization in the last hundred years. Electricity is produced mostly by combusting fossil fuels, but this practice has induced extensive environmental issues. With a gradual exhaustion of fossil fuels, an urgent need has raised wide concerns for the development of clean energies, such as hydrogen energy and solar energy for electricity generation. These renewable energies are weather dependent, so the development of efficient and environmentally friendly electricity storage are essential devices for the development of clean renewable energies. Rechargeable metal-air batteries, especially water-based metal-air batteries, have received increasing concern with the

\footnotetext{
* Corresponding author. Tel/Fax: +86-411-84379182; E-mail: zhuxf@dicp.ac.cn

All the authors appreciate the financial supports from the National Natural Science Foundation of China (91545202, U1508203), the Strategic Priority Research Program of the Chinese Academy of Sciences (CAS) (XDB17000000), the Youth Innovation Promotion Association of the Chinese Academy of Sciences and the Liaoning Revitalization Talents Program (XLYC1807066).

DOI: S1872-2067(19)63514-X | http://www.sciencedirect.com/science/journal/18722067 | Chin. J. Catal., Vol. 41, No. 3, March 2020
} 
safety and high specific-energy density. However, such energy technologies still cannot be applied commercially because of a lack of active and stable bifunctional electrocatalysts, which can accelerate the rates of the oxygen reduction reaction (ORR) and oxygen evolution reaction (OER). The ORR process happened with the formula $\mathrm{O}_{2}+2 \mathrm{H}_{2} \mathrm{O}+4 \mathrm{e}^{-} \rightarrow 4 \mathrm{OH}^{-}$in alkaline media or $\mathrm{O}_{2}+4 \mathrm{H}^{+}+4 \mathrm{e}^{-} \rightarrow 2 \mathrm{H}_{2} \mathrm{O}$ in acidic media. The OER process happened with the formula $4 \mathrm{OH}^{-} \rightarrow \mathrm{O}_{2}+2 \mathrm{H}_{2} \mathrm{O}+4 \mathrm{e}^{-}$in alkaline media or $2 \mathrm{H}_{2} \mathrm{O} \rightarrow \mathrm{O}_{2}+4 \mathrm{H}^{+}+4 \mathrm{e}^{-}$in acidic media. The ORR process occurs on the discharging process in rechargeable metal-air batteries. Whereas for the OER process, which occurs on the charging process, hydroxide ions or $\mathrm{H}_{2} \mathrm{O}$ molecules release electrons and are oxidized to form oxygen molecules. ORR and OER that involve multielectron complex processes are kinetically sluggish; so many efforts are focused on developing effective electrocatalysts to accelerate ORR and OER processes [1-4].

The ORR overpotential is closely related to the adsorption and desorption process of $\mathrm{O}_{2}$ and its products, including the intermediate and final products on the catalyst surface. ORR is an extremely complex reaction process that involves multiple steps of elementary reactions and various intermediates $\left(\mathrm{OH}^{*}\right.$, $\mathrm{OOH}^{*}$ and $\mathrm{HOOH}$, etc.). It is very challenging to explore the real reaction mechanism. There are two different possible mechanisms depending on the different modes of oxygen adsorption and dissociation barrier on the three-phase interface of the reaction in an alkaline medium, as shown in Fig. 1(a). The first one is the two-electron process, which produces a peroxide intermediate: $\mathrm{O}_{2}+\mathrm{H}_{2} \mathrm{O}+2 \mathrm{e}^{-} \rightarrow \mathrm{HO}_{2}^{-}+\mathrm{OH}^{-}$; the second is the four-electron process, which produces $\mathrm{OH}^{-}: \mathrm{O}_{2}+2 \mathrm{H}_{2} \mathrm{O}+4 \mathrm{e}^{-} \rightarrow$ $4 \mathrm{OH}^{-}$. In general, a two-electron pathway with peroxide formation appears with the end-on $\mathrm{O}_{2}$ adsorption, which occurs primarily on carbonaceous materials. The direct four-electron pathway may be happened with the bidentate $\mathrm{O}_{2}$ adsorption, which occurs mainly on the noble metals. For metal oxide materials, different ORR pathways exist rely on various factors. Research of intermediates on the catalyst surface is an efficient and accurate means to identify the rate-determining step. As

(a)
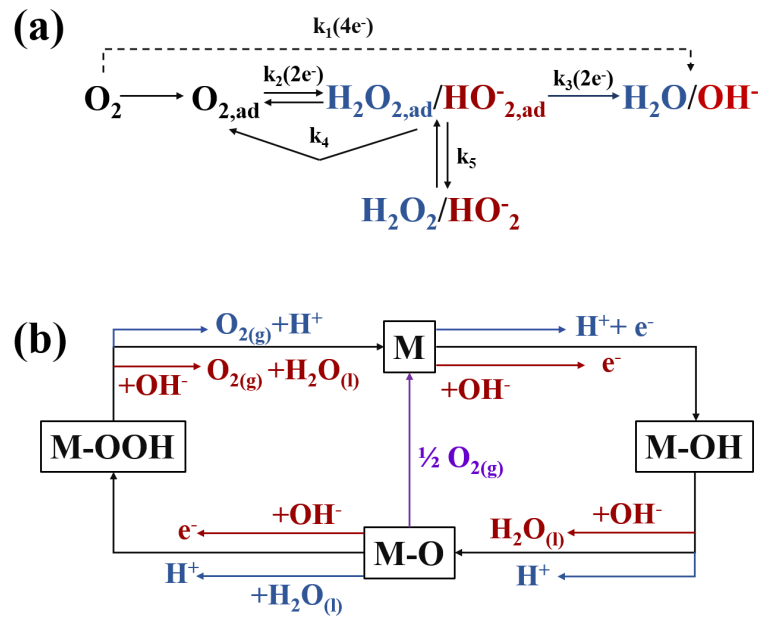

Fig. 1. (a) One possible ORR mechanism in acidic (blue) and alkaline (red) electrolytes. (b) One possible OER mechanism in acidic (blue) and (red) alkaline electrolytes. shown in Fig. 1(a), increased $\mathrm{OOH}^{-}$means a greater possibility of the two-electron process. The direct four- electron process is expected to be more active and efficient than the two-electron process [5-9].

In the ORR process, Pt and Pt alloys with an overwhelming catalytic performance are commonly regarded as the state-of-the-art catalysts [10-12]. However, their scarcity, high cost and limited stability restricts the large-scale commercial applications of Pt-based electrocatalysts. On one hand, some strategies were developed to reduce the precious metal contents have been developed. Researches have indicated that the active sites on the specific facets have higher activity. For example, Zhang et al. [13] prepared Pt cubic nanocages with controllable surface structure. This cost-effective catalyst exhibited distinctive catalytic activities. In this manner, developing stable, inexpensive and non-precious ORR electrocatalysts with an excellent catalytic performance have attracted increased attention, which included carbon-based catalysts, transition metal oxides materials and so on [14-19].

The OER process involves the formation of oxygen-oxygen bond, which include four sequential proton-coupled electron transfer steps. These steps have intrinsic sluggish kinetics and thermodynamics. Many possible mechanisms for the OER process have been proposed, and a wide acceptable mechanism is shown in Fig. 1(b) [20]. The active site is simply marked as "M". The pathways of the oxygen formation may differ in the acidic and alkaline electrolytes. Using an alkaline electrolyte as an example, the active site $\mathrm{M}$ combines with $\mathrm{OH}^{-}$and releases electrons to form $\mathrm{MOH}, \mathrm{MO}$ and $\mathrm{MOOH}$ intermediates gradually, then $\mathrm{MOOH}$ decomposes to $\mathrm{O}_{2}$ and reverts to $\mathrm{M}$. Combining two $\mathrm{M}-\mathrm{O}$ to generate $\mathrm{O}_{2}$ is also possible, depending on the M-O bond energy. The bonding interaction on the intermediates (such as $\mathrm{MOH}, \mathrm{MO}$, and $\mathrm{MOOH}$ ) is critical for the efficiency of the electrocatalysts. From such a perspective, the M-O bond strength should not be too strong or too weak. Catalysts with an intermediate $\mathrm{M}-\mathrm{O}$ bond strength have a good catalytic activity [21]. For carbon materials, the change on the electronic density is helpful to alter the OER activity. More information is shown in the subsequent section.

The theoretical thermodynamic potential of OER is $1.23 \mathrm{~V}$ (vs RHE) at $298 \mathrm{~K}$, which may lead to the oxidation of many metals. Precious metal oxides, such as $\mathrm{IrO}_{2} / \mathrm{RuO}_{2}$, are widely considered to be the reference electrocatalysts for the OER due to their high catalytic activity [22,23]. However, similar to Pt-based electrocatalysts for ORR, the high price and poor stability limit the large-scale commercial applications of $\mathrm{IrO}_{2}$ and $\mathrm{RuO}_{2}$ electrocatalysts. Therefore, non-precious OER electrocatalysts composed, such as earth-abundant elements materials, transition metal compounds and carbon-based nanomaterials, have been broadly studied over 10 years. In an acidic medium, it is difficult to avoid the performance degradation for most of non-precious metal electrocatalysts. Simultaneously carbon may be oxidized to carbon dioxide and carbon monoxide instead of oxygen evolution for carbon-based OER electrocatalysts in acid medium. Thus, non-precious metal OER electrocatalysts are studied mostly in the alkaline medium [24-26].

As mentioned above, the OER and ORR have different reac- 
tion mechanisms; thus, they require active electrocatalysts with different characteristics. Excellent bifunctional electrocatalysts can accelerate the two sluggish reactions and improve the efficiency of the metal-air batteries simultaneously. However, it is challenging to design a bifunctional electrocatalyst that is active and stable in two directions. This reversible reaction pair with different rate limiting steps requires different active sites and valence state of metals. In addition, the oxidization of ORR active sites at OER operating conditions, agglomeration of nanoparticles and corrosion of carbon support need to be solved for the development of bifunctional electrocatalysts. A series of reviews have been published on ORR or OER electrocatalysts in the past 20 years [27,28]. However, few reviews have been published on bifunctional electrocatalysts. It is difficult to clearly show the critical factors affecting the performance of bifunctional electrocatalysts by a summarization on materials and preparation methods. Therefore, in this minireview, to describe a clear outline of the critical factors, the strategies to improve the electrocatalytic activity of bifunctional electrocatalysts are summarized into two groups, i.e. the improvement of intrinsic activity and apparent activity, as shown in Fig. 2. The intrinsic activity refers to the catalytic activity for a single active site, which can be changed with the crystal structure and electronic structure (Fig. 2). For one particular material, the change of intrinsic activity is difficult and sometime is uncontrollable. Besides, the apparent activity can be modified from varies of morphology configuration and the synergistic effect between different components in the composites. For bifunctional electrocatalysts, it is important to improve the quantity and activity of OER and ORR active sites through the skillful micro-nanostructural design. This work will focus on the design and fabrication of micro-nano structures of bifunctional electrocatalysts according to the previous researches. A variety of influence factors, including crystal structure, electronic structure, morphology effect, and synergisitic effect are summarized in the following sections. Some typical examples are introduced and discussed to illustrate how the intrinsic activity and apparent activity are affected by micro-nano structures.

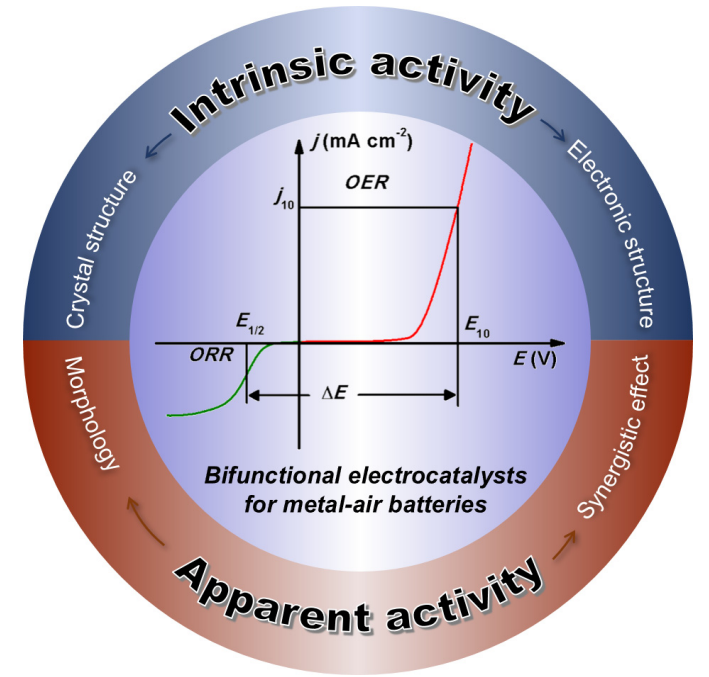

Fig. 2. The strategies of the enhancement on the bifunctional electrocatalytic activity.
We wish this work would help researchers quickly catch the keypoints related to the development of bifunctional electrocatalysts.

\section{Influence factors of intrinsic activity}

The intrinsic activity of the bifunctional electrocatalysts is crucial, which can be changed by adjusting the electronic structure and crystal structure. On one hand, electronic structure can be affected by some crystallographic factors. On the other hand, crystal structure is also an important factor for the intrinsic activity.

\subsection{Electronic structure}

Electronic structure has a significant influence on the oxygen and the intermediates adsorption. The adsorption energy is crucial for the activation energy, rate-limiting step and the reaction path. For the transition metal electrocatalysts, the $3 d$ electron configurations and energy are crucial for the activity. For the metal compound crystal such as perovskite oxides, the electronic energy can be changed by the crystal field, which may affect the linear combination with $02 p$ orbitals. Some crystallographic factors such as the strength of metal-oxygen bond, lattice strain, oxygen defects, cations doping, valence state of cations etc. Here we just show how the electronic structure and corresponding electrocatalytic activity are affected by adjusting the strength of metal-oxygen bond and lattice strain as examples. For the carbon materials and some amorphous compounds, the heteroatom doping and topological defects which are significant ways for the change of electronic structure, will be briefly introduced.

\subsubsection{Metal-oxygen bonds}

The metal-oxygen bonds with mixed ionic-covalent character have a significant effect on the electronic structure. The electron density of the active sites varies with the element and valence, which affects the adsorption and desorption energy with the reactant and intermediates. Therefore, the metal-oxygen bonds are important for the metal-containing catalysts. The linear combination of metal (M) $d$ orbitals and $02 p$ orbitals form an $e_{\mathrm{g}}$ state and $t_{2 \mathrm{~g}}$ state according to the molecular orbital theory. In the octahedral environment of perovskite oxides, as shown in Fig. 3(a) [29], the $e_{\mathrm{g}}$ state represents the $\sigma$-bonding and $\sigma^{*}$-antibonding states that are overlapped spatially by the $d_{\mathrm{z}^{2}-\mathrm{r}^{2}}$ and $d_{\mathrm{x}}{ }^{2}-\mathrm{y}^{2}$ lobes of the transition metal $\mathrm{d}$ orbitals with those of adjacent $02 p$ orbitals, whereas the $t_{2 g}$ represents the $\pi$-bonds and $\pi^{*}$-antibonds through spatial overlap with the $d_{\mathrm{xy}}, d_{\mathrm{yz}}$ and $d_{\mathrm{xz}}$ lobes of the transition metal $d$ orbitals and the $02 p$ orbitals. The combination degree of metals and oxygen states depends on the transition metal ion and its oxidation states. According to the principle of energetic similarity in the molecular orbital theory and band theory, the degree of metal-oxygen hybridization will increase with the energy of the metal $d$ states close to that of the $02 p$ states by increasing the electronegativity of the transition metal. Based on the Sabatier principle, the strength of metal-oxygen bonds for ideal bifunc- 
(a)

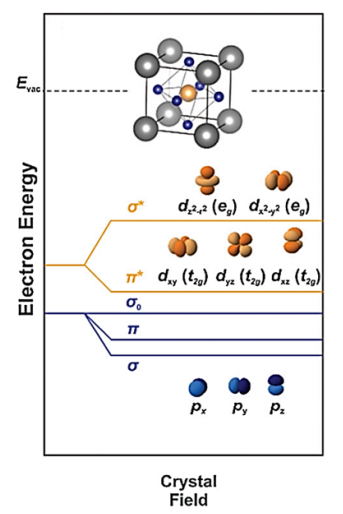

(b)

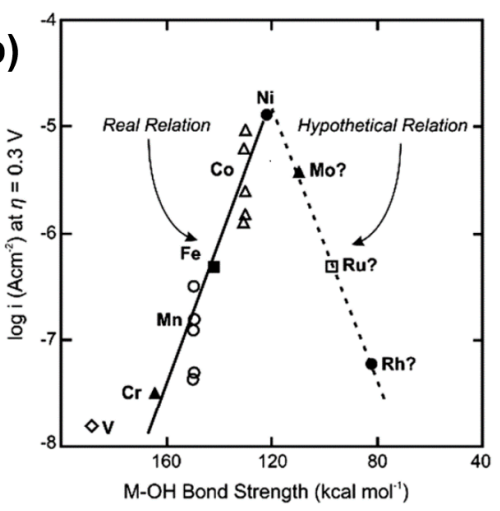

(c) $\quad \mathrm{Cr}^{3+}\left(d^{3}\right) \quad \mathrm{Mn}^{3+}\left(d^{4}\right) \quad \mathrm{Fe}^{3+}\left(d^{5}\right) \quad \mathrm{Co}^{3+}\left(d^{6}\right) \quad \mathrm{Ni}^{3+}\left(d^{7}\right)$

\begin{tabular}{|c|c|c|c|c|c|}
\hline High spin & & $\begin{array}{ll}e_{g} & \uparrow \\
t_{2 g} \uparrow \uparrow \uparrow & \uparrow\end{array}$ & $e_{g} \uparrow \uparrow \uparrow$ & 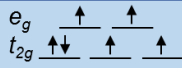 & $e_{g} \frac{\uparrow}{t_{2 g}} \uparrow \uparrow \uparrow$ \\
\hline $\begin{array}{l}\text { Intermediate } \\
\text { spin }\end{array}$ & & & & $e_{g} \stackrel{\uparrow}{t_{2 g} \uparrow \downarrow} \uparrow \downarrow \uparrow$ & \\
\hline Low spin & $\begin{array}{l}e_{g}-\uparrow \uparrow \\
t_{2 g} \uparrow \uparrow \uparrow\end{array}$ & $\begin{array}{l}e_{g} \\
t_{2 g}\end{array}$ & $\begin{array}{l}e_{g} \\
t_{2 g} \uparrow \downarrow\end{array}$ & $\begin{array}{l}e_{g} \\
t_{2 g} \uparrow \downarrow \\
\uparrow \downarrow\end{array}$ & $e_{g} \frac{\uparrow}{t_{2 g}} \uparrow \downarrow \uparrow \downarrow \uparrow \downarrow$ \\
\hline
\end{tabular}

Fig. 3. (a) The crystal field splitting between orbitals M $3 d$ and $02 p$ atomic orbitals formed the molecular orbitals. Reprinted with permission [29]. Copyright 2015 The Royal Society of Chemistry. (b) The relationship between the log $i$ at $0.3 \mathrm{~V}$ overpotential and M-OH bond strength. Reprinted with permission [30]. Copyright 1983 American Chemical Society. (c) Potential transition metal 3d electron configurations for LaMO 3 perovskite oxides (M = Cr, Mn, Fe, Co, Ni) for different spin states at room temperature. Adapted with permission [29]. Copyright 2015 The Royal Society of Chemistry.

tional electrocatalysts should not be too strong or too weak. The volcano trend of the relationship between the $\mathrm{M}-\mathrm{OH}$ bond strength and the catalytic activity has been reported by Bockris et al. [30], as shown in Fig. 3(b). Yang et al. [28] proposed that eg-occupancy can be the ORR/OER activity descriptor for perovskite oxides because it can indicate the strength of metal-oxygen bonds from the molecular orbital theory. The Fig. 3 showed at room temperature the $d$-electron configurations and typical spin states for $\mathrm{LaMO}_{3}(\mathrm{M}=\mathrm{Cr}, \mathrm{Mn}, \mathrm{Fe}, \mathrm{Co}, \mathrm{Ni})$ [28]. The descriptor assumes that the number of electrons in the $\sigma^{*}$ states determines the strength of the metal-oxygen bond and the activity is in line with the Sabatier principle. The activity is optimal when $e_{\mathrm{g}}=1$. The metal oxygen bond is strong at a low eg occupancy $\left(e_{\mathrm{g}}<1\right)$, which favors the ORR and is weak at a high eg occupancy $\left(e_{\mathrm{g}}>1\right)$, which favors the OER. The eg is also related to the spin state. The energy of the $t_{2 g}$ states is lower than that of the $e_{\mathrm{g}}$ states at a low-spin configuration when the splitting energy is larger than the electron pairing energy on the d orbitals.

\subsubsection{Strain}

By changing the orbital overlap, strain has a significant effect on the oxides electronic structure. The $\mathrm{LaCoO}_{3}$ (LCO) thin films were pulsed laser deposited on a conductive interlayer ( $\mathrm{La}_{0.67} \mathrm{Sr}_{0.33} \mathrm{MnO}_{3}$ (LSMO)) and various substrates $\left(\mathrm{SrTiO}_{3}\right.$ (STO), $\left(\mathrm{LaAlO}_{3}\right)_{0.3}\left(\mathrm{Sr}_{2} \mathrm{AlTaO}_{6}\right)_{0.7} \quad$ (LSAT), $\mathrm{LaAlO}_{3} \quad$ (LAO), respectively) to investigate the strain effect [31]. The lattices mismatch between the catalysts and substrates cause the epitaxial strain. The investigation indicated that the compressive strain is not conducive to the improvement of the activity, which was attributed to the reduction of electronic conductivity by the compressive strain. However, different from that of occurring on LCO films, the $\mathrm{LaNiO}_{3}$ (LNO) films with high conductivity at room temperature showed an increase of the activity towards the compressive strain. Lee et al. [32] investigated the strain influence of the perovskite $\mathrm{LaNiO}_{3}$ on both the ORR and OER. By using different lattice-mismatched substrates, the strain degree was controlled from $-2.2 \%$ to $2.7 \%$, as shown in Fig. 4(a). The performance of ORR and OER can be enhanced as the LAO $\left(\mathrm{LaAlO}_{3}\right)$ substrate was used to produce a strain of $-1.2 \%$ in the $\mathrm{LaNiO}_{3}$, as shown in Fig. 4(b) and (c). A direct relationship between the strain and the performance is shown in Fig. 4(d) and (e). The investigation showed that the compressive strain enhances the activity of ORR and OER, which was attributed to a splitting of the $e_{\mathrm{g}}$ orbitals induced by the compressive strain. The splitting of the $e_{\mathrm{g}}$ orbitals decreases the energy of $e_{\mathrm{g}}$-center and results in the weaker strength of the metal-oxygen bond, thus enhances the electrocatalytic activity. The density functional theory (DFT) on the LNO (001) surface was used to prove the above conclusion. Cooper et al. [33] further explored the influences of strain on the ORR and OER thermodynamic pathways on the LNO (001) surface. Strain affects the Ni-O hybridization on the surface. Tensile strain blocks the formation of $-\mathrm{O}_{2} \mathrm{H}$ intermediate, which increases the $\Delta G$ of ORR and decreases the ORR activity. On the other hand, the tensile strain increases the adsorption energy of hydrogen species. However, the enhancement is not beneficial for the OER process.

\subsubsection{Heteroatom doping}

Carbon materials have been investigated extensively as electrocatalysts owing to their inexpensive cost, unique morphology and excellent electrical conductivity properties [34]. The catalytic activities of pristine carbon materials, including 

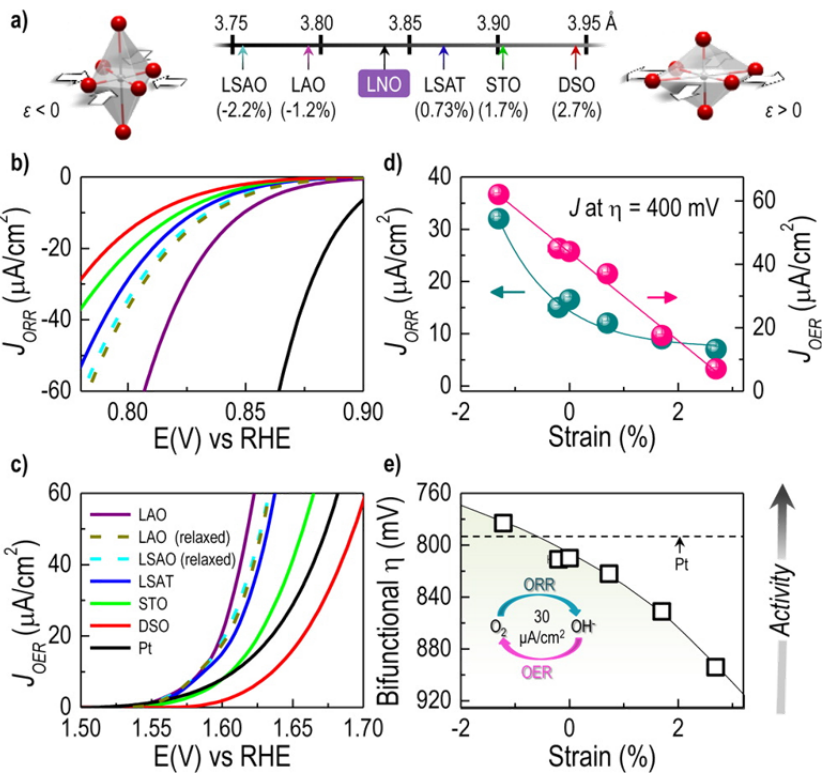

Fig. 4. (a) Lattice parameters and associated biaxial strain for LNO on different substrates. (b, c) ORR and OER activities of strained $\mathrm{LaNiO}_{3}$. (d Relationship between ORR/OER activities (overpotentials of $0.4 \mathrm{~V}$ ) and strain. (e) Relationship between bifunctionality at $30 \mu \mathrm{A} \mathrm{cm}-2$ for reactions and strain. Reprinted with permission [32]. Copyright 2016 American Chemical Society.

carbon blacks, graphene and carbon nanotubes (CNTs), tend to be lower compared with those of metal oxides for the reason of pristine carbon materials usually take a two-electron pathway. This is because that the electrically neutral carbon materials have high adsorption and desorption free energy to the reactants and intermediates. Heteroatom doping is an effective strategy to change the charge-density and electronic-structure. By doping with a heteroatom, the electrical neutrality of the $\mathrm{sp}^{2}$ hybrid carbon is destroyed and the spin density is increased, which yields a catalytic process from a two-step two-electron process to a direct four-electron process. The heteroatoms with different electronegativity can affect the material properties to different extents. Among heteroatom doped carbon materials, nitrogen-doped carbon materials have been investigated extensively because various precursors and synthesis methods can be used for electrocatalysts preparation [35]. The introduction of a secondary element on the nitrogen-doped carbon basis favors a modulation of charge density and an increase in catalytic activity. Zhang and co-workers [36] reported a promotion mechanism on the $\mathrm{N}$ and $\mathrm{S}$ dual-doped hierarchical carbon material. The larger electronegativity of $\mathrm{N}$ (3.04) provides adjacent $C$ (2.55) atoms with a positive change. They proposed that if the charge density or spin density of carbon atoms exceeds 0.15 , the carbon atoms can be considered as activated sites in the catalytic process [37]. The introduction of $\mathrm{N}$ can increase the number of active carbons. The similar electronegativity of $C(2.55)$ and $S(2.58)$ results in a small change in atomic charge distribution. Even though the activity of $S$ is weaker than that of $\mathrm{C}$, the synergistic effect of $\mathrm{S}$, N-dual-doping still improves the activities observably. Qiao et al. [38] prepared S-doped N-C nanotubes. The introduction of S in the ma- terial changes the spin density of the adjacent $\mathrm{C}$ atoms and the carbon atoms in other positions. As a result, a large number of atoms are activated to accelerate the OER process. B as an electron-deficient atom produces the effective active sites [39]. Similarly, S-doping and P-doping also activate the ORR and OER processes in some materials $[40,41]$.

\subsubsection{Topological defects}

Heteroatom-doping and edge-induced topological defects can redistribute the electron density, and increase the adsorption of intermediates. Yi et al. [42] removed nitrogen from a $\mathrm{N}$-doped precursor to obtain the graphene with carbon defects. The ORR, OER, and HER activities of the carbon defects material are higher than that of the N-doped graphene. Wei et al. [43] investigated the influence of heteroatom-doping, edge-rich and topological defects on the electrocatalytic activity. The prepared ultrathin hexagonal graphene flakes are self-assembled into a porous and layered stent. The catalyst exhibited a large number of holes and edge defects verified by Raman spectra and was used as a model system to study the influence of heteroatom-doping, edge effects and topological defects. As shown in Fig. 5(a), several models, including a pyrrolic (PR), quaternary nitrogen on the edge $(\mathrm{Q})$, a quaternary nitrogen in the bulk phase (QN), a pyridinic nitrogen (PN), a five-carbon ring (C5), a seven-carbon ring (C7), and a five-carbon ring adjacent to a seven-carbon ring $(\mathrm{C} 5+7)$ were proposed as the possible active sites. The sites of topological defects at the edge were more active than those of the doping and edge sites. The DFT calculation indicates that the pentagon and heptagon carbon rings decrease the overpotential remarkably. The overpotentials of ORR and OER were decreased to 0.14 and $0.21 \mathrm{~V}$, respectively, by $\mathrm{C} 5$ adjoining $\mathrm{C} 7$ to form a curved configuration $\mathrm{C} 5+7$. This $\mathrm{C} 5+7$ active site shows much lower overpotentials than other active sites, as shown in Fig. 5(b). This material exhibits a good ORR electrocatalytic activity in alkaline and acidic solutions. The $E_{\text {onset }}$ and $E_{1 / 2}$ are 0.89 and $0.77 \mathrm{~V}$ (vs RHE), respectively, which are lower than the commercial $20 \mathrm{wt} \% \mathrm{Pt} / \mathrm{C}$ in alkaline solution. The number of (a)

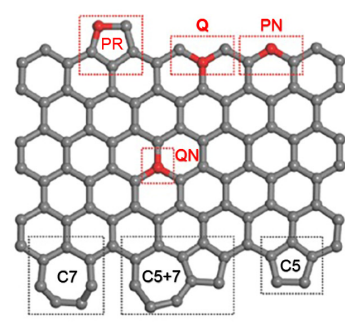

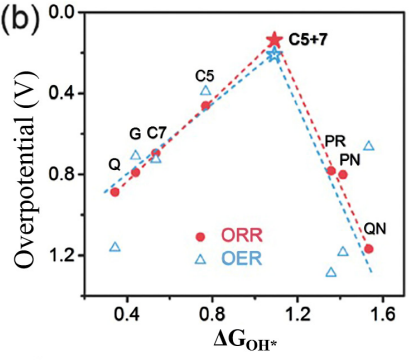

Fig. 5. DFT calculations of ORR/OER activities for metal-free nanocarbon materials. (a) Schematic graphene nanoribbon with different types of N-doping or topological defects. PR: pyrrolic nitrogen; PN: pyridinic nitrogen; Q: quaternary nitrogen on the edge; QN: quaternary nitrogen in the bulk phase; C5: five-carbon ring; C7: seven-carbon ring; C5+7: five-carbon ring adjacent to seven-carbon ring. (b) ORR and OER volcano plots of overpotential versus adsorption energy of $\mathrm{OH}^{*}$, which indicates the $\mathrm{C} 5+7$ as the optimal active site for both ORR and OER electrocatalysis. Reproduced with permission [43]. Copyright 2016, Wiley-VCH. 
transfer electrons approached 4 in $0.10 \mathrm{M} \mathrm{HClO}_{4}$. The OER activity was good and the potential gap $(\Delta E)$ between the $E_{1 / 2}$ of ORR and the $E_{10}$ of OER was $0.9 \mathrm{~V}$. Wang et al. [44] prepared the porous graphene structure enriched with edge topological defects. The edge topological defects act as the active sites and enhance the activity. The topological defects produced in situ by pre-oxidation and hydrogen etching without $\mathrm{N}$-doping.

\subsection{Crystal structure}

Transition metal materials, including transition metal oxides or hydroxides, have attracted considerable attention in the electrocatalytic applications of ORR and OER because of their abundant reserves, various valence states and flexible structures and compositions. [45] Crystal structure is also one of the most important factors for the transition metal catalytic activity. Different types of crystal structures and oxygen vacancies may change the intrinsic activity of transition metal electrocatalysts.

\subsubsection{Types of crystal structure}

Among numerous transition metal materials, perovskite-type materials are one kind of the highest efficiency electrocatalysts in alkaline media because of their flexible physical and chemical properties, superior ionic and electronic conductivity and exceptional thermal stability. Perovskites tend to have the formula $\mathrm{ABO}_{3}$. The A site is occupied by rare earth, alkaline or alkaline-earth metal ions with larger cation radii and is more electropositive coordinated with twelve-fold oxygen anions. The $\mathrm{B}$ site is occupied by smaller transition metal ions, such as $\mathrm{Mn}^{3+/ 4+}, \mathrm{Co}^{2+/ 3+/ 4+}, \mathrm{Fe}^{3+/ 4+}, \mathrm{Cr}^{3+/ 4+}$ etc., that are coordinated with six-fold oxygen anions. Electronic and geometric structures are affected by the substitution of A or B site cations with different sizes and valence states. The substitution would result in non-stoichiometric oxygen, including oxygen deficiencies and oxygen excess denoted as $\mathrm{A}_{1-x} \mathrm{~A}^{\prime}{ }_{x} \mathrm{~B}_{1-y} \mathrm{~B}^{\prime}{ }_{y} \mathrm{O}_{3-\delta}$ [46].

Owing to the varying composition and variable physical and chemical properties by substituting $\mathrm{A}$ - and B-sites, the perovskite-type materials provide ORR and OER active sites in alkaline medium. Typically, the $\mathrm{Ba}_{0.5} \mathrm{Sr}_{0.5} \mathrm{Co}_{0.8} \mathrm{Fe}_{0.2} \mathrm{O}_{3-\delta}$ (BSCF5582) with a cubic perovskite structure was used as the highly active solid oxide fuel cells cathode material owing to the high activity on the ORR process. BSCF5582 is a high active OER electrocatalyst comparable with the state-of-the-art $\mathrm{IrO}_{2}$ [47]. The ORR and OER activity of BSCF5582 can be further improved after heat-treating it in $\mathrm{O}_{2}$ atmosphere at elevated temperatures. The improvement is attributed to the increased in crystallinity of the whole cubic perovskite structure and the removement of the spinel phase between amorphous layer and cubic perovskite particle bulk[47]. Recently, the cobalt-free perovskite oxides, $\mathrm{BaFeO}_{3-\delta}$ and $\mathrm{BaM}_{0.05} \mathrm{Fe}_{0.95} \mathrm{O}_{3-\delta}(\mathrm{M}=\mathrm{Ti}, \mathrm{Zr}$ and $\mathrm{Ce}$ ) were used as the cathode of the intermediate-temperature solid oxide full cells [48]. Through changing the doping amount of $\mathrm{Zr}$, cubic $\mathrm{BaZr}_{x} \mathrm{Fe}_{1-x} \mathrm{O}_{3-\delta}$ perovskite can be obtained, and it exhibits high OER activity comparable to $\mathrm{Ba} 0.5 \mathrm{Sr}_{0.5} \mathrm{Co}_{0.8} \mathrm{Fe}_{0.2} \mathrm{O}_{3-\delta}$ [49].
In addition to the perovskite-type materials, the transition metal hydroxides were widely used as the OER catalysts. Our group developed an atomic-scale topochemical transformation route to prepare the Fe-doped $\beta-\mathrm{Ni}(\mathrm{OH})_{2}$, which shows higher catalytic activity than the $\gamma-\mathrm{Ni}(\mathrm{OH})_{2}$ counterpart [50].

Layered double hydroxides (LDHs) or anionic/hydrotalcitelike clays are a family of layer materials composed of divalent and trivalent metal cations coordinated to hydroxide anions or guest anions (e.g. $\mathrm{CO}_{3}{ }^{2-}$ ) [51]. LDHs have been investigated widely as OER electrocatalysts owing to their tunable metal composition and ratio, guest anions and interlayer spacing [52]. The poor electronic conductivity of the LDHs can be improved by combining them with carbon materials. The formed nanocomposite structure favours an enhancement of the electrocatalytic activity of the materials.

Recently, Duan et al. developed a bifunctional electrocatalyst with ternary $\mathrm{NiCo}^{\mathrm{II}} \mathrm{Fe}$-LDHs grafted on $\mathrm{N}$-doped graphene oxide (N-GO) [53]. Materials with a three-dimensional (3D) open structure were prepared by the LDHs grown in situ on defective and N-doped wrinkle GO. As shown in Fig. 6(a), part of LDH nanosheets grown vertically to the substrate formed the array-like structured $\mathrm{Ni}_{2} \mathrm{Co}^{\mathrm{III}} \mathrm{Fe}-\mathrm{LDH} / \mathrm{N}-\mathrm{GO}$. At first, the LDH grew parallel to the substrate because of the electrostatic attraction. With the growth of LDH, the LDH laminates were repulsive to LDH/N-GO composites and tended to grow vertically. The array-like structure is conductive to the gas diffusion and the increase of surface area. The hysteresis loop area of NiCo ${ }^{I I I} \mathrm{Fe}-\mathrm{LDH} / \mathrm{N}-\mathrm{GO}$ is larger than other materials, as shown in Fig. 6(b). The multi-stage pores and hierarchical structure may provide more active sites to increase the catalytic activity. The Tafel slope of this material is shown in Fig. 6(c) and (d), which indicating an excellent electrocatalytic activity. The onset potentials of the ORR and OER are $0.88 \mathrm{~V}$ vs RHE and $1.41 \mathrm{~V}$ vs RHE in $0.1 \mathrm{M}$ $\mathrm{KOH}$, and this electrocatalyst shows a $\Delta E$ of $0.769 \mathrm{~V}$. The excellent OER activity of the material is attributed to the hierarchical structure design to exposing amounts of $\mathrm{Ni}$ and $\mathrm{Fe}$ active sites. The introduction of $\mathrm{Co}^{3+}$ tuned the electronic structure, which can improve the ORR activity of the material. This work demonstrated the possibility of using LDHs as ORR/OER bifunctional electrocatalysts. Despite this significant work, it is still urgently required to develop bifunctional electrocatalysts with a low overpotential and a good stability. Beside of the transition metal materials mentioned above, other transition metal-based materials, including amorphous metal oxides, nitrides, phosphates and sulfides, were developed as a bifunctional electrocatalyst recently. A family of amorphous bimetallic oxide-graphene hybrid was prepared through a general three-stage synthesis strategy [54]. About 5 nm Prussian blue (PB) or FeCo Prussian blue analogues (PBAs) nanocrystals were grown on polyethylenimine (PEI)/graphene oxide (GO) hybrid. Then the FeCo PBAs nanocrystals were decomposed into amorphous FeCo oxide nanoparticles at optimized temperature. The prepared materials with the amorphous $\mathrm{Fe}_{0.5} \mathrm{Co}_{0.5} \mathrm{O}_{x}$ nanoparticles showed superior ORR and OER activity. Shan et al. [55] prepared $\mathrm{Fe}_{2} \mathrm{P} @ \mathrm{Fe}_{4} \mathrm{~N}$-coupled nanoparticles embedded in $\mathrm{N}$-doped carbons by carbonizing 

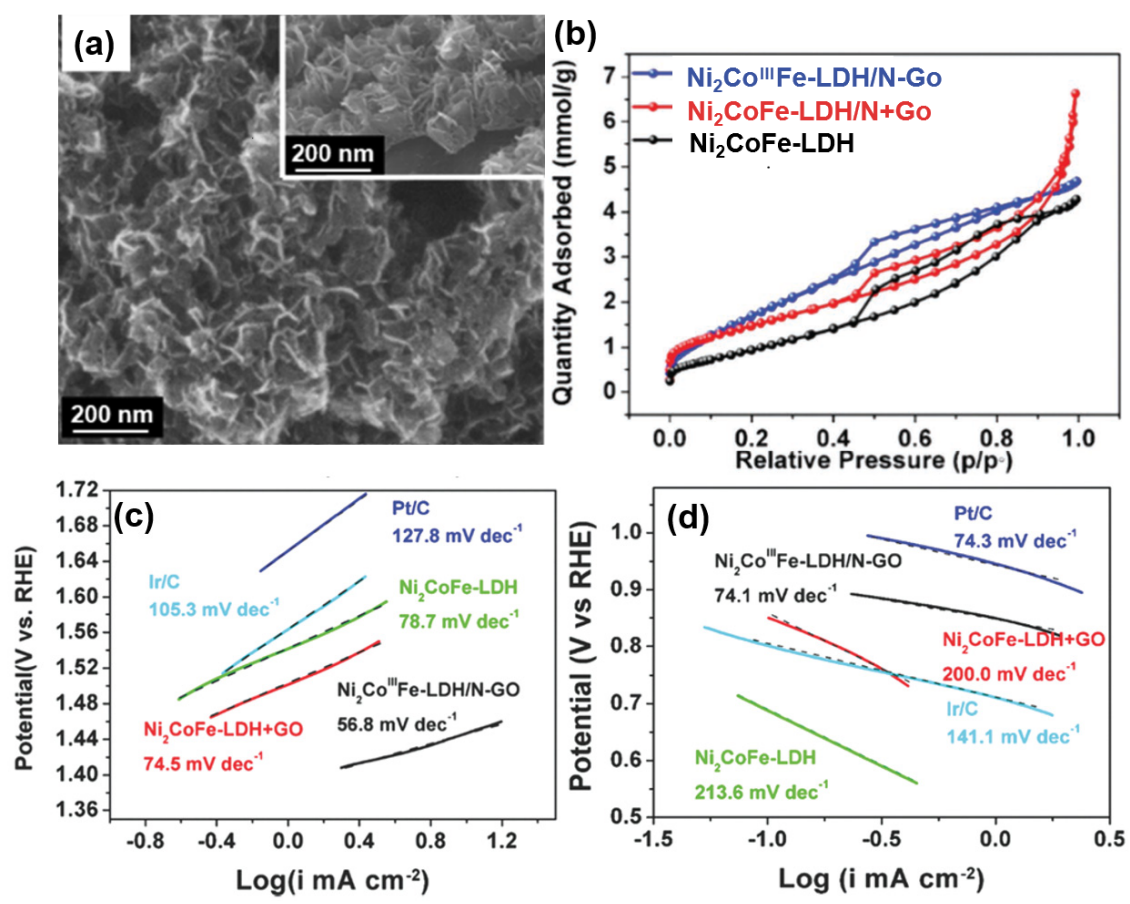

Fig. 6. (a) Scanning electron microscopy (SEM) images of prepared NiCo ${ }^{I I I} \mathrm{Fe}-\mathrm{LDH} / \mathrm{N}-\mathrm{GO}$. (b) $\mathrm{N}_{2}$-adsorption/desorption isotherms of the prepared $\mathrm{Ni}_{2} \mathrm{Co}^{\mathrm{III}} \mathrm{Fe}-\mathrm{LDH} / \mathrm{N}-\mathrm{GO}, \mathrm{Ni}_{2} \mathrm{CoFeLDH}+\mathrm{GO}$, and $\mathrm{Ni}_{2} \mathrm{CoFe}-\mathrm{LDH}$. (c,d) OER and ORR Tafel slopes of all samples. Reproduced with permission [53]. Copyright 2017, Wiley-VCH.

prepared planar multidirectional porphyrin polymer (Fe-Triphenylphosphine (TPP)-Covalent porphyrin frameworks (CPFs)). Fe-TPP-CPFs used rigid iron(III)5,10,15,20-tetrakis(p-bromophenyl)porphyrin (Fe-TBPP) and 1,3,5-benzenetriboronic acid trivalent alcohol ester (BTA) as building blocks. This material carbonized at nitrogen atmosphere in $800{ }^{\circ} \mathrm{C}, \mathrm{Fe}_{2} \mathrm{P} / \mathrm{Fe}_{4} \mathrm{~N} @ \mathrm{C}-800$, exhibited great ORR catalytic activity comparable to commercial $\mathrm{Pt} / \mathrm{C}$ catalysts and efficient OER and hydrogen evolution reaction (HER) activities. $\mathrm{NiFe}$ disulfides were used as the precursor in situ electrochemical oxided to form $\mathrm{NiFe}(\mathrm{Oxy})$ hydroxides as the electrocatalysts. The resultant electrocatalyst exhibited a good OER catalytic activity with an overpotential of $\sim 297 \mathrm{mV}$ at 10 $\mathrm{mA} \mathrm{cm}{ }^{-2}$ [56]. This material was composited with CNTs and used in a Zn-air battery test, and showed a good activity and stability during 150 charge-discharge cycles. Part of the high activity was attributed to the surface $S$ residues according the theoretical calculation.

\subsubsection{Oxygen vacancy}

Oxygen vacancies exist widely in transitional metal oxides due to their low formation energy. The oxygen vacancies can adjust the adsorption of oxygen species by increasing the electron transfer from the oxygen vacancies to the metal $d$-band. In addition, based on the studies of solid oxide fuel cells and oxygen permeation membranes, the oxygen vacancies signifiacntly impact the material properties such as the electronic structure, ionic/electronic conductivity, magnetic property, etc. Usually, oxygen vacancies are introduced by substituting the A and B sites with elements with lower valence states on the perovskite-type materials. For example, introducing the alkaline earth elements such as $\mathrm{Ca}^{2+}$ or $\mathrm{Sr}^{2+}$ into the A site of $\mathrm{La}\left(\mathrm{Fe}, \mathrm{Co}, \mathrm{Ni}_{3} \mathrm{O}_{3}\right.$ based perovskite oxides can increase the oxygen mobility in the lattice [57]. Extremely high temperature and specific atmosphere may also contribute to the formation of oxygen vacancies. Some reducing regents were used to produce oxygen-vacancies. For example, $\mathrm{NaBH}_{4}$ was used to introduce oxygen vacancies into NiFe-OOH [58]. Our group treated the $\mathrm{Sr}_{2} \mathrm{Fe}_{1.3} \mathrm{Ni}_{0.2} \mathrm{Mo}_{0.5} \mathrm{O}_{6-\delta} \delta$ (SFNM) at different atmospheres (e.g., air and $\mathrm{Ar}$ ), and found that the sample treated in Ar with more oxygen vacancies exhibited higher OER activity than that treated air. The DFT calculations indicated that the oxygen vacancies increase the adsorption energy of $\mathrm{H}_{2} \mathrm{O}$ to boost the activity [59]. Wu et al. prepared an oxygen-deficient $\mathrm{BaTiO}_{3-\delta}$ electrocatalyst in an extremely high temperature and vacuum atmosphere [60]. This oxygen-deficient $\mathrm{BaTiO}_{3-\delta}$ perovskite oxide exhibited high catalytic activities for ORR and OER simultaneously in the alkaline electrolyte. They found that reactant $\left(\mathrm{OH}^{-}\right)$adsorption and charge transfer are accelerated by oxygen vacancies in the perovskite oxide. The formation energy of oxygen vacancy is inverse to the distance between the $02 p$-band center and the Fermi level. Therefore, the formation energy of the oxygen vacancy can be decreased by changing the distance through the substitution at the A and B sites. Chen et al. [61] reported a serious of nonstoichiometric $\mathrm{CaMnO}_{3-\delta}(0<\delta \leq 0.5)$, as shown in Fig. 7 (a). With an increase in oxygen vacancies, the $\mathrm{MnO}_{6}$ octahedral in $\mathrm{CaMnO}_{3}$ was transformed into $\mathrm{MnO}_{5}$ square pyramids in $\mathrm{CaMnO}_{2.5}$. According to the polarization curves of the nonstoichiometric $\mathrm{CaMnO}_{3-\delta}$ shown in Fig. 7(b), the perovskite oxides exhibited the highest ORR/OER activity and stability with $\delta$ near 0.25 and an average Mn valence close to 
(a)
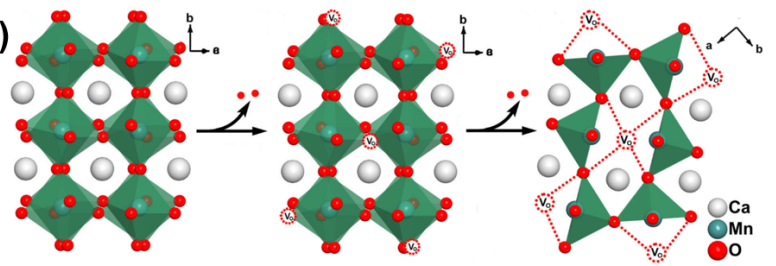

(b)

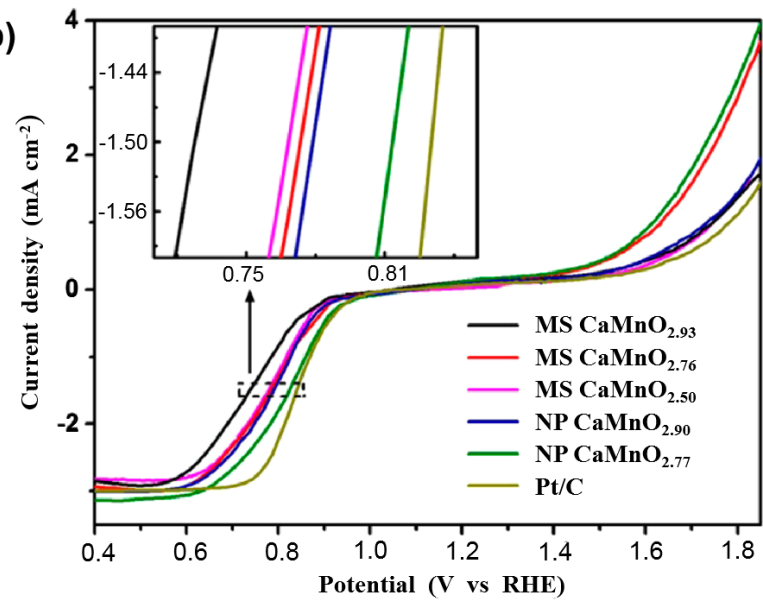

Fig. 7. (a) Schematic representation of the crystal frameworks of stoichiometric and oxygen-deficient perovskites that show a transition from stoichiometric $\mathrm{CaMnO}_{3}$ to nonstoichiometric $\mathrm{CaMnO}_{2.76}$ and $\mathrm{CaMnO}_{2.5}$; (b) Bifunctional OER/ORR performances of $\mathrm{CaMnO}_{3-\delta}$ microspheres (MS), nanoparticles (NP), and the comparative Pt/C in $\mathrm{O}_{2}$-saturated alkaline solution. The inset enlarges the ORR curves in the half-wave potential region. Reprinted with permission [61]. Copyright 2014 American Chemical Society.

3.5. Single-crystal $\mathrm{CoO}$ nanorods with oxygen vacancies on the $\{111\}$ facet showed ideal ORR and OER activities with an onset potential, $E_{1 / 2}$ and $E_{10}$ of $0.96,0.85 \mathrm{~V}$ and $1.56 \mathrm{~V}$ (vs RHE), respectively [62]. The overall potential gap $\left(\Delta E=E_{10}-E_{1 / 2}\right)$ is $0.71 \mathrm{~V}$, which is better than most bifunctional ORR/OER electrocatalysts reported in literatures. However, excessive oxygen vacancies may change the crystal structure and reduce the catalytic activity.

\section{Influence factors of apparent activity}

Except the improvement of the intrinsic catalystic activity by changing the crystal and electronic structure, the increase in the apparent catalytic activity is also effective for the application of electrocatalysts in metal-air batteries. The apparent activity is mainly related to the the morphology effects and synergistic effects. A skillful design on morphology can provide more active sites to increase the apparent activity. The synergistic effects between different components can improve the apparent activity through constructing a composite with an optimized nano structure.

\subsection{Morphology effect}

The nano-structured electrocatalyst have high electrocatalytic activity because the higher surface area exposed more active sites and provided efficient electron transfer routes.
Various nano structures with different morphologies have been investigated extensively in oxygen bifunctional electrocatalysis. $\mathrm{Fu}$ et al. designed a catalyst with a structure of CoFe alloy nanoparticles embedded in bamboo-like $\mathrm{N}$-doped carbon nanaotubes (CNTs) entangled with reduced GOs. The material exhibits a good ORR/OER catalytic activity and stability [63]. Through the functional modification of hollow nanomaterials, more materials with a high performance have been developed. Urchin-like $\mathrm{NiCo}_{2} \mathrm{~S}_{4}$ sub-micron spheres with nano- and micro-sized structures was prepared by a facile one-pot method [64]. This material exhibits a good bifunctional electrocatalytic activity owing to its urchin-like nano structure, composition, and unique d-electronic configuration. For the reason of the bulk of catalyst has poor catalytic activity compared with the surface of the catalyst, the morphology with more surface area and active sites is significant for the electrocatalytic activity. We will introduce some typical morphologies in the following sections.

\subsubsection{Wire-like materials}

As mentioned above, CNTs is one of the important carbon materials for the bifunctional electrocatalysts. A series of 1-D materials derived from CNTs were prepared with good ORR and OER activities. Xiao et al. [65] combined a composite with cobalt-iron bimetallic nitrides and $\mathrm{N}$-doped multi-walled carbon nanotubes (Co-Fe-N@MWCNT). The nitride nanoparticles were dispersed on the multi-walled carbon nanotubes. On the one hand, the multi-walled carbon nanotubes dispersed the nitride nanoparticles to provide more active sites for the ORR and OER. On the other hand, the multi-walled carbon nanotubes provided a great electronic conductivity and connect for the nitride nanoparticles. A novel core-shell $\mathrm{N}$-doped carbon material with a core of pristine CNTs and a shell of N-doped carbon layers exhibited excellent electrocatalytic activities in ORR and OER. The surface-enriched nitrogen atoms provided more ORR and OER active sites. The complete inner walls od the CNTs played the role of effective support and electronic conduction channel [66]. Nanda et al. [67] co-embedded N-doped carbon nanotubes (N-CNTs) and $\mathrm{Fe}^{-} \mathrm{Fe}_{3} \mathrm{C}$ nanostructure in the B-doped mesoporous carbon nanostructures (BFNCNTs) through the pyrolysis of ferrocence-melamine and ferrocence-triphenyl borane (TPB) sequentially. The SEM image of the obtained materials (Fig. 8(a)) revealed that the BFNCNTs were rougher than the NCNTs obtained by the pyrolysis of melamine and ferrocene. The transmission electron microscopy (TEM) image shown in Fig. 8(b) indicated that the NCNTs and the $\mathrm{Fe}-\mathrm{Fe}_{3} \mathrm{C}$ was co-embedded in the boron-doped carbon nanostructures. The $\mathrm{N}_{2}$ adsorption-desorption isotherm shown in Fig. 8(c) exhibited the macro- and meso- porosity of the structure and the high specific Brunauer-Emmett-Teller (BET) surface area (about $272 \mathrm{~m}^{2} \mathrm{~g}^{-1}$ ). The X-ray diffraction (XRD) shown in Fig. 8(d) also confirmed the existence of $\mathrm{Fe}$ and $\mathrm{Fe}_{3} \mathrm{C}$. From the Raman spectra in Fig. 8(e), the $I_{\mathrm{D}} / I_{\mathrm{G}}$ ratio of BFNCNTs is higher than others is, indicating more defects on BFNCNTs. More active sites enhanced the ORR and OER activities. The $\Delta E\left(=E_{10}\right.$ - $E_{1 / 2}=0.8 \mathrm{~V}$ ) is much lower than several 


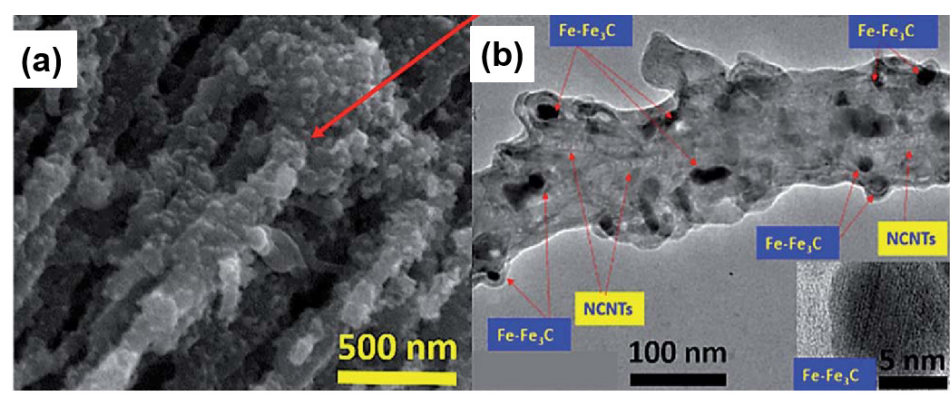

(c)
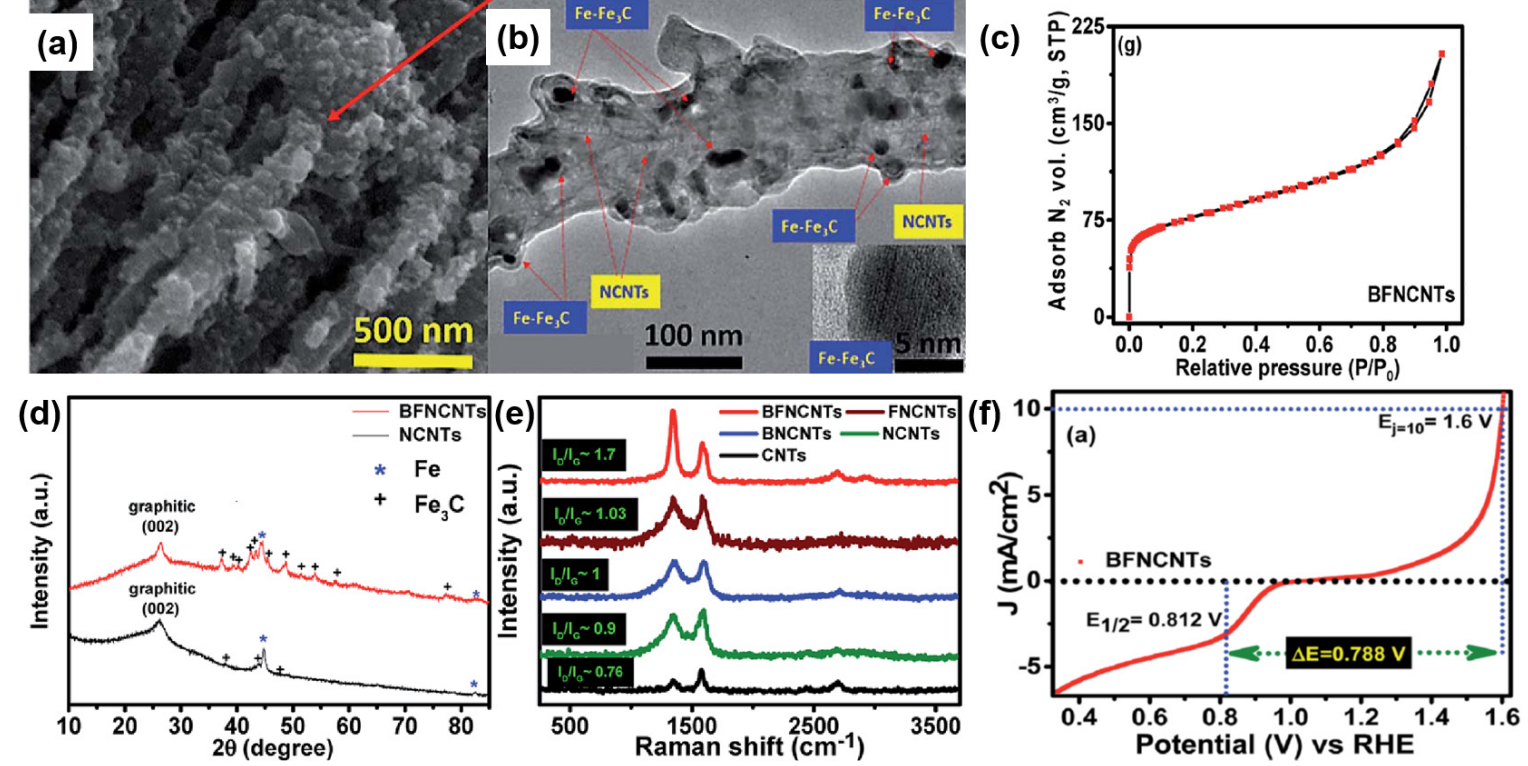

Fig. 8. (a) SEM micrographs of BFNCNTs. (b) TEM micrographs of BFNCNTs. (c) Nitrogen adsorption-desorption isotherm BFNCNTs. (d) XRD patterns of NCNTs and BFNCNTs. (e) Raman spectra of pristine CNTs, NCNTs, BNCNTs (boron-doped carbon coated NCNTs), FNCNTs (Fe-Fe 3 C containing carbon coated NCNTs) and BFNCNTs. (f) The overall linear sweep voltammetry polarization curve on BFNCNTs for complete oxygen electrochemistry $\left(\triangle \mathrm{E}=E_{10}-E_{1 / 2}\right)$. Reprinted with permission [66]. Copyright 2017 The Royal Society of Chemistry.

hetero-atom/co-doped carbon materials as shown in Fig. 8(f). The fabricated $\mathrm{Al}$ prototype battery with the electrocatalysts powered a light emitting diode.

\subsubsection{Nanosheet materials}

Nanosheet materials have caught widely concern because of their huge surface area indicating that more active sites can be put on. Typical examples such as LDHs, graphene and the graphene derivatives have been widely used as the electrocatalysts. A 3D network hybrid (NGSH) with N-doped graphene and single-walled CNTs (SWCNT) was fabricated by CVD growth on a layered double hydroxide [68]. This 3D interconnected network formed by the simultaneous growth of graphene and SWCNTs has a high dispersion of graphene, CNTs and the $\mathrm{N}$-containing functional groups. The NGSHs with a large specific surface area (812.9 $\left.\mathrm{m}^{2} \mathrm{~g}^{-1}\right)$ and a high electron conductivity (53.8 S cm-1) exhibit an excellent ORR catalytic activity compared with commercial $20 \mathrm{wt} \% \mathrm{Pt} / \mathrm{C}$ catalysts, and a good OER catalytic activity. Ni-doped $\mathrm{CoO}$ nanosheets with numerous nanopores at the micro-and nanoscale using $\mathrm{ZnO}$ nanosheets as sacrificial templates also exhibited a great improvement in ORR catalytic activity [69]. Hierarchical porous carbon sheets with boron (B)-doped Co-N-C active sites were synthesized by a soft template self-assembly pyrolysis method [70]. The prepared materials with crumpled two-dimensional sheets and an internal porous structure exhibit good ORR and OER catalytic activities. The Co- $\mathrm{N}-\mathrm{C}$ provided the active sites, while the B introduction activated the electron transfer around the active sites to accelerate the reaction kinetics. The Zn-air battery with this material as the air electrode exhibited an excellent performance $(\sim 1.4 \mathrm{~V}$ open-circuit potential and $\sim$ $100.4 \mathrm{~mW} \mathrm{~cm} \mathrm{~cm}^{-2}$ peak power density) and durability (128 cycles for $14 \mathrm{~h}$ of operation). A Co and $\mathrm{N}$ codoped ultrathin porous carbon nanosheet (Co-N-PCN) was prepared through a direct carbonization of graphene oxide sandwiched cobalt ion adsorbed polyaniline-co-polypyrrole (PACP) precursors [71]. The ultrathin porous carbon nanosheets exposed abundant active sites, in which the Co- $\mathrm{N}_{x}-\mathrm{C}$ active sites was produced by the carbonization of PACP, and the graphene ensured the charge transfer and electrode conductivity. Benefiting from the larger surface area and the synergistic effect between the abundant active sites and the high conductivity, the material presented excellent bifunctional electrocatalytic activity with the $\Delta E\left(\Delta E=E_{10}-E_{1 / 2}\right)$ as low as $0.81 \mathrm{~V}$ in $0.1 \mathrm{M} \mathrm{KOH}$.

\subsubsection{Nano sphere/box materials}

Exposing more active sites on the bifunctional electrocatalysts is beneficial to the enhancement of the ORR and OER activities. Some investigators have fabricated several of skillful designed three-dimensional structural catalysts. Hollow sphere and box are the common structures used in the preparation of catalysts. CoMn double hydroxide hollow spheres as ORR, OER and HER catalysts were prepared [72]. The materials exhibited superior ORR and OER activity with the $\Delta E\left(\Delta E=E_{10}-E_{1 / 2}\right)$ of $0.794 \mathrm{~V}$ in $0.1 \mathrm{M} \mathrm{KOH}$. Because this material has ultrathin surface and the hollow sphere structure, the all-solid-state Zn-air battery composed of the material exhibited excellent stability with $14 \mathrm{~h}$ cycling measurements unchanged. A novel $\mathrm{Co}_{3} \mathrm{O}_{4} / \mathrm{Co}-\mathrm{Fe}$ oxide double-shelled nanobox was synthesized through an anion-exchange reaction between ZIF-67 nanocube precursors and $\left[\mathrm{Fe}(\mathrm{CN})_{6}\right]^{3-}$ ions and subsequent annealing treatment, as shown in Fig. 9(a) [73]. The double-shelled nanobox structure (DSNBs) yielded a better electrocatalytic performance than single-shelled nanoboxes (SSNBs) for ORR and OER in alkaline solution as shown in Fig. 9(b) and (c). Fig. 8(d) indicated that the material stability was 
also good.

\subsection{Synergistic effect}

Usually, it is feasible to find an electrocatalyst with a high activity toward ORR or OER, but difficult to find an electrocatalyst with both high activities toward ORR and OER, for the reason of the two reactions require different active sites or valence states of metal ions. To resolve this problem, researchers proposed combining the advantages of two single-functional electrocatalysts to form a bi-functional electrocatalyst, in which the ORR and OER activities can be increased by the advanced synergistic effects.

Noble metals have high activities but high costs for ORR or OER. The composites of transition metal compounds and noble metals can reduce the entire material cost. A reasonable micro-nano composite structure designing can yield a remarkable synergistic effect between the two types of materials. Researchers deposited $\mathrm{Pd}$ on the bonded $\mathrm{MnO}_{2}$ nanowires and carbon nanotubes (CNTs). The material exhibited superior ORR and OER catalytic activity and stability [74]. The single Pd atom dispersed on the 3D interwoven $\alpha-\mathrm{MnO}_{2}$ and CNTs displayed the 5-fold higher activity than that of Pd-based electrocatalysts the state-of-the-art operated in alkaline medium. The activity was two magnitudes higher than that of Pd/CNT owing to the synergistic effect between the Pd atom and the surrounding $\mathrm{Mn}$ sites on the $\mathrm{MnO}_{2}$ surface. The introduction of $\mathrm{Ru}$ as NiRu-LDHs also further enhanced the electrocatalytic activity of $\mathrm{Ni}(\mathrm{OH})_{2}$. Chala et al. [75] developed an efficient and stable bifunctional electrocatalyst composed with the NiRu-LDHs and silver nanoparticles. The reason for the high bifunctional electrocatalytic activity was partially attributed to the strong synergetic effect between LDHs and Ag nanoparticles. The strong synergetic effect affected the site activity and population on the catalyst surface. The strong synergetic effect between FeCo, FeCoNi alloys and N-doped carbon species also exhibited excellent ORR and OER activities. Wang et al. [76] reported a kind of bifunctional oxygen electrocatalyst with the $\mathrm{Fe}_{0.5} \mathrm{Co}_{0.5}$, $\mathrm{Fe}_{0.5} \mathrm{Co}_{0.4} \mathrm{Ni}_{0.1}$ alloys encapsulated in the nitrogen-doped carbon materials. The material was used as the air cathode of a $\mathrm{Zn}$-air battery showing excellent charge/discharge ability and outstanding cycling stability (360 cycles).

The most common form of bifunctional oxygen electrocatalysts is the combination of transition metal materials (including oxides, hydroxides, nitrides, sulfides etc.) with carbon materials. Transition metal materials have poor electronic conductivities but could provide abundant active sites, whereas carbon materials have high electronic conductivity. A skilful design of the composite structure can improve the catalytic activity by a synergistic effect. Many investigators have made significant (a)

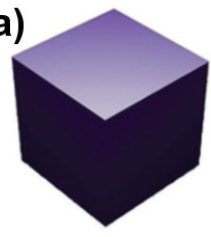

ZIF-67 NCs

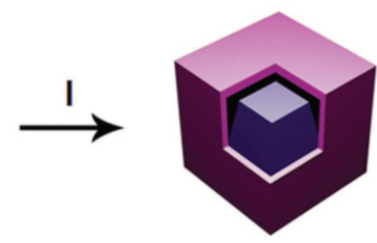

ZIF-67/Co-Fe PBA YSNCs

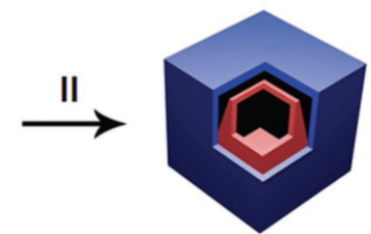

$\mathrm{Co}_{3} \mathrm{O}_{4} / \mathrm{Co}-\mathrm{Fe}$ oxide DSNBs
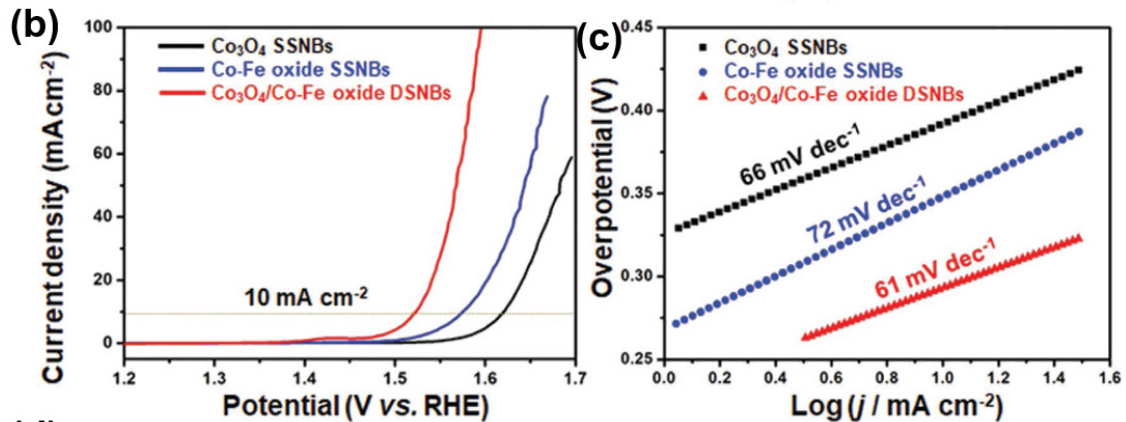

(d) 12

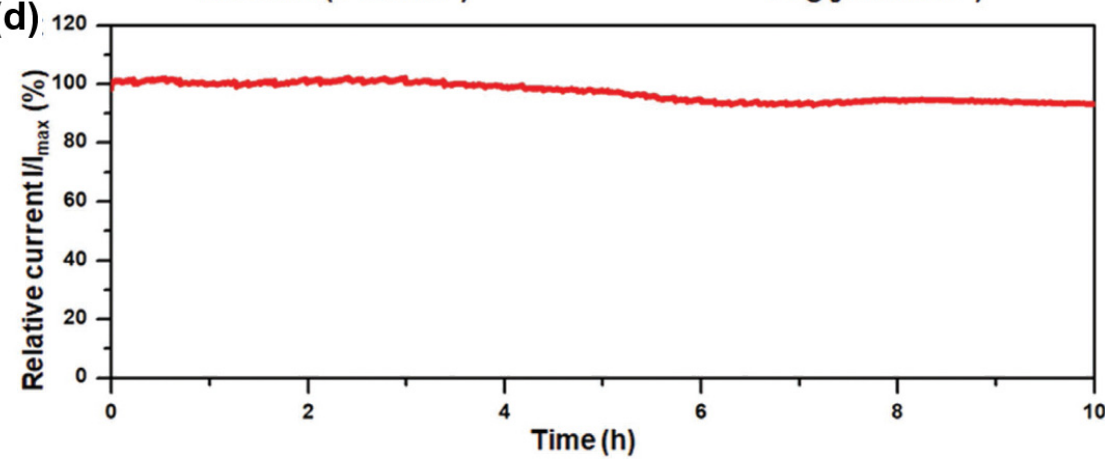

Fig. 9. (a) $\mathrm{Co}_{3} \mathrm{O}_{4} / \mathrm{Co}$-Fe oxide DSNBs (double-shelled nanobox structure) formation process. LSV curves (b) and Tafel plots (c) of $\mathrm{Co}_{3} \mathrm{O}_{4} / \mathrm{Co}_{-}-\mathrm{Fe}$ oxide DSNBs, Co-Fe oxide SSNBs, and $\mathrm{Co}_{3} \mathrm{O}_{4}$ SSNBs. (d) Chronoamperometry curve of $\mathrm{Co}_{3} \mathrm{O}_{4} / \mathrm{Co}$-Fe oxide DSNBs at $325 \mathrm{mV}$ overpotential. Reproduced with permission [73]. Copyright 2018, Wiley-VCH. 
contributions in this field. The perovskite/carbon composites display an excellent electrocatalytic activity toward ORR and OER. Spinel, LDHs and other metal oxides have been used extensively in composites to improve the activity. Liu et al. [77] prepared an excellent ORR/OER bifunctional electrocatalyst of $\mathrm{ZnCo}_{2} \mathrm{O}_{4} / \mathrm{N}-\mathrm{CNT}$ (N-doped CNT). The N-CNTs can couple with $\mathrm{Zn}^{2+}$ and $\mathrm{Co}^{2+}$, thus the $\mathrm{ZnCo}_{2} \mathrm{O}_{4}$ crystallites are anchored on $\mathrm{N}$-CNTs and are dispersed as quantum dots (3.0-3.5 nm). This structure can expose more active sites and ensure electron transport. Low Tafel slopes were achieved for ORR and OER in this work, which indicated an excellent electrocatalytic activity. The synergistic effect needs effective electronic conductivity. A core/shell structure with $\mathrm{NiFe}$ alloy core and $\mathrm{NiFeO}_{x}$ shell exhibited high OER activity owing to the synergistic effect. The metal core accelerated the electron conduction between the active sites and the oxides also protected the metal core from oxidation [78]. In addition, metal-organic framework (MOF) derived carbon materials and carbonized MOFs are widely used as the ORR and OER catalysts. Recently, a novel bifunctional oxygen electrocatalyst, MOF-N-doped carbon nanotubes (MOF-NCNTs), was prepared through the carbonized of ZIF-67 [79]. The porous cage structure of MOF-NCNTs provided high surface area. The NCNTs obtained through the pyrolysis of ZIF-67 enhanced the electronic conductivity. The directly heat-treatment of ZIF-67 ensured the well connect between the active sites and NCNTs. The carbonized material give the mass and charge transfer routes for the OER and ORR process. The synergistic effect resulted a high ORR and OER activity and stability. Dong et al. [80] deposited $\mathrm{TiO}_{2}$ onto the surface of nano- $\mathrm{B}_{4} \mathrm{C}$. The introduction of $\mathrm{TiO}_{2}$ promoted the graphitization of $\mathrm{B}_{4} \mathrm{C}$, resulting in the both excellent ORR and OER activities.

In addition, Fu et al. [63] combined CoFe alloy, N-doped carbon nanotubes (NCNTs) and reduced graphene oxide (rGO) to a novel material with CoFe alloy nanoparticles embedded in $\mathrm{N}$-doped bamboo-like CNTs tangled with reduced graphene oxide (rGO) nanosheets (CoFe/N-GCT). As shown in Fig. 10(a), the CoFe Prussian blue analogues (PBA) was used as the precursor of CoFe alloy nanoparticles. The melamine was carbonized to the plane $\mathrm{C}_{3} \mathrm{~N}_{4}$ and the NCNTs successively to fabricate the 3D nanostructure. The NCNTs connected with the rGO and the alloy nanoparticles confirmed the high exposed surface area and electronic conductivity. The morphology of the material is shown in Fig. 10(b)-(e). The CNTs was tangled with the rGO nanosheet and embedded into the CoFe alloy nanoparticles. The XRD shown in Fig. 10(f) also confirmed the existence of CoFe alloy and the graphitic carbon. The Raman spectra (Fig. $10(\mathrm{~g}))$ with $I_{\mathrm{G}} / I_{\mathrm{D}}$ reflects the low concentration of defects and better conductivity. With the synergistic effect of plentiful active sites and high electronic conductivity, the ORR and OER activity were enhanced drastically as show in Fig. 10(h).

\section{Summary and outlook}

The ORR and OER are important reactions for many energy storage and conversion processes. However, ORR and OER processes are kinetically sluggish, thus more efforts are needed to develop active electrocatalysts to speed up the two reactions.

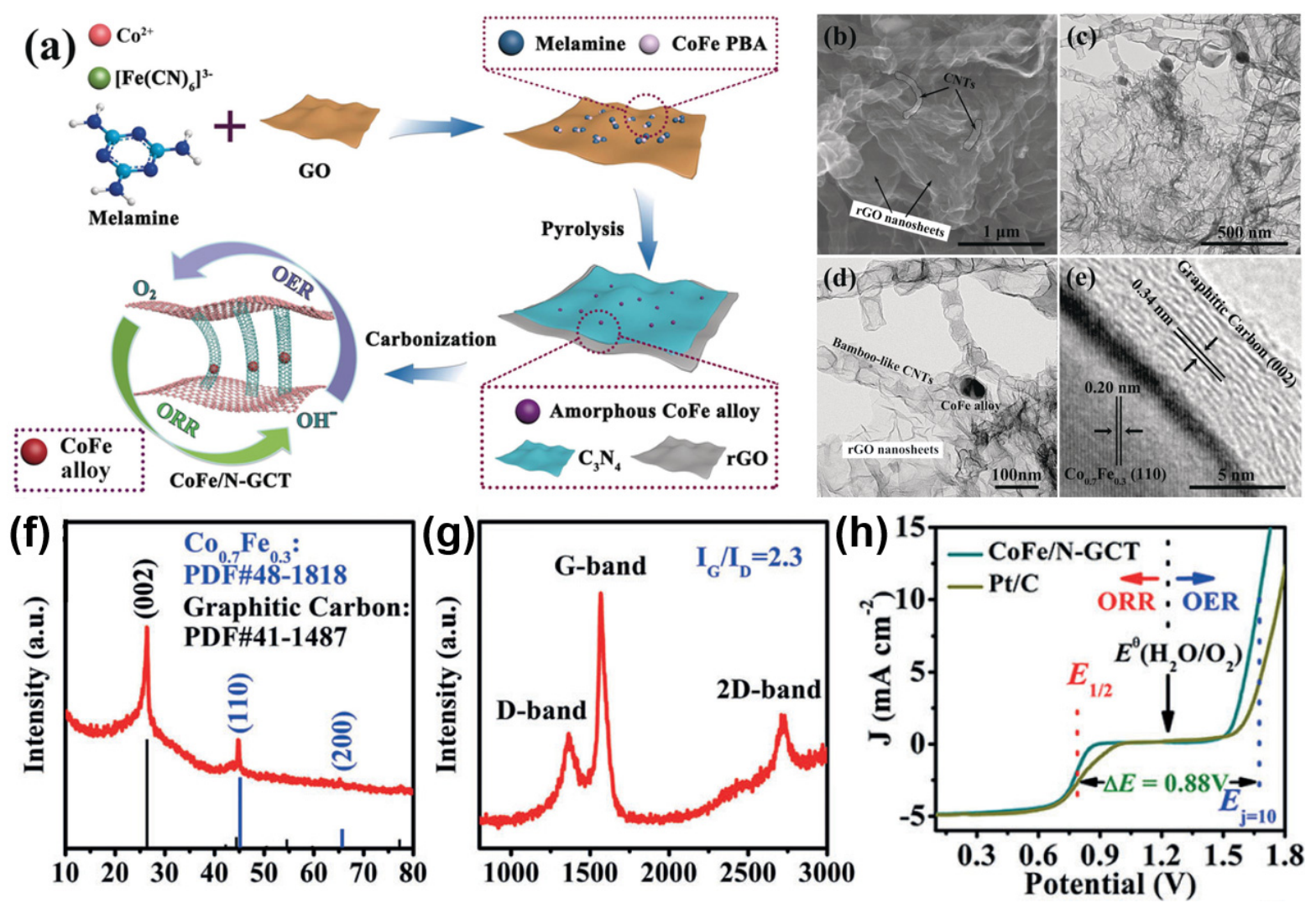

Fig. 10. Synthetic scheme (a), SEM (b), TEM (c, d), HRTEM (e) images, XRD pattern (f), and Raman spectrum (g) of CoFe/N-GCT. (h) LSV curves of $\mathrm{CoFe} / \mathrm{N}-\mathrm{CNT}$ and $\mathrm{Pt} / \mathrm{C}$ in the full OER/ORR region in $\mathrm{O}_{2}$-saturated 0.1M KOH. Reproduced with permission [63]. Copyright 2019, Wiley-VCH. 
One of the most useful strategies, metal-air batteries, can be commercially applied only with high active ORR and OER bifunctional electrocatalysts to decrease the voltage gap and improve the energy efficiency. In recent years, extensive exploration has been conducted on cost-effective and high performance bifunctional electrocatalysts. These bifunctional electrocatalytic materials include carbon-based materials, transition metal materials and composites. Two strategies to improve the activity of the bifunctional electrocatalysts include an increase in the intrinsic activity and the apparent activity. The intrinsic activity can be improved by changing the crystal structure and electronic structure. For example, the medium-strength of metal-oxygen bond can accelerate the electrocatalytic process. Doping with heteroatoms in carbon-based material can change the electric neutrality of the carbon to accelerate the reaction process. The apparent activity can be improved by changing the morphology and utilizing the synergistic effect. Morphology fabrication with special nanostructures is the most often used strategy to improve the electrocatalytic activity. In this case, electrocatalysts have high surface area, a large number of active sites and a considerable electronic conductivity. At the same time, the synergistic effect between components of composite electrocatalysts on accelerating the catalytic process cannot be ignored. An increased number of materials that were designed by considering the micro-nanostructures were synthesized as bifunctional electrocatalysts for metal-air batteries.

We propose that the development of novel bi-functional electrocatalysts for ORR and OER requires the cooperative development of synthesis methods with the fine adjustment of electrocatalyst micro-nano structures and more cognition about underlying reaction mechanism. First, the enhancement of intrinsic activity and apparent activity causing by the elaborate adjustment of structures are significant factors to evaluate of the ORR and OER activities. In addition, deep understanding of the reaction mechanism with well-designed characterization methods would help in the enhancement of bifunctional electrocatalysts activity [81]. We expect the development of excellent bifunctional electrocatalysts could accelerate the commercialization of rechargeable metal-air batteries for the storage and conversion of renewable energies.

\section{Acknowledgments}

All the authors appreciate the financial supports from the National Natural Science Foundation of China (91545202, U1508203), the Strategic Priority Research Program of the Chinese Academy of Sciences (CAS) (XDB17000000), the Youth Innovation Promotion Association of the Chinese Academy of Sciences and the LiaoNing Revitalization Talents Program (XLYC1807066).

\section{References}

[1] D. U. Lee, P. Xu, Z. P. Cano, A. G. Kashkooli, M. G. Park, Z. Chen, J. Mater. Chem. A, 2016, 4, 7107-7134.

[2] Z.-F. Huang, J. Wang, Y. Peng, C.-Y. Jung, A. Fisher, X. Wang, Adv. Energy Mater., 2017, 7, 1700544.

[3] D. Chen, C. Chen, Z. M. Baiyee, Z. Shao, F. Ciucci, Chem. Rev., 2015, $115,9869-9921$.

[4] Y. Huang, Y. Wang, C. Tang, J. Wang, Q. Zhang, Y. Wang, J. Zhang, Adv. Mater., 2018, 1803800.

[5] J. K. Nørskov, J. Rossmeisl, A. Logadottir, L. Lindqvist, J. Phys. Chem. $B, \mathbf{2 0 0 4}, 108,17886-17892$.

[6] M. Mukherjee, M. Samanta, P. Banerjee, K. K. Chattopadhyay, G. P. Das, Electrochim. Acta, 2019, 296, 528-534.

[7] C. Deng, R. He, W. Shen, M. Li, T. Zhang, Phys. Chem. Chem. Phys., 2019, 21, 6900-6907.

[8] S. Sharma, C. Zeng, A. A. Petersona, J. Chem. Phys., 2019, 150, 041704.

[9] Y. Zhuang, J. Chou, P.-Y. Liu, T.-Y. Chen, J. Kai, A. Hu, H.-Y. T. Chen, J. Mater. Chem. A, 2018, 6, 23326-23335.

[10] Y. Nie, L. Li, Z. Wei, Chem. Soc. Rev., 2015, 44 2168-2201.

[11] M. L. Liu, Z. P. Zhao, X. F. Duan, Y. Huang, Adv. Mater., 2019, 31,

\section{Graphical Abstract}

Chin. J. Catal., 2020, 41:390-403 doi: S1872-2067(19)63514-X

\section{Micro-nanostructural designs of bifunctional electrocatalysts for metal-air batteries}

Fang Shi, Xuefeng Zhu*, Weishen Yang

Dalian Institute of Chemical Physics, Chinese Academy of Science;

University of Chinese Academy of Sciences

Cost-effective and highly active ORR and OER catalysts are critical for the utilization of renewable electric energy. Intrinsic activity and apparent activity are closely related to the micro-nano structures of bifunctional electrocatalysts.

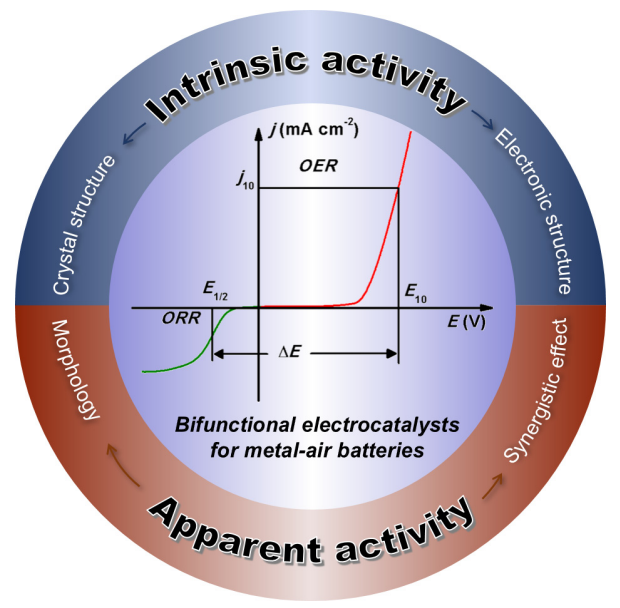


1802234

[12] N. K. Chaudhari, J. Joo, B. Kim, B. Ruqia, S. Choi, K. Lee, Nanoscale, 2018,10, 20073-20088.

[13] L. Zhang, L. T. Roling, X. Wang, M. Vara, M. Chi, J. Liu, S. Choi, J. Park, J. A. Herron, Z. Zie, M. Mavrikakis, Y. Xia, Science, 2015, 349, 412-416.

[14] H. Shi, Y. Shen, F. He, Y. Li, A. Liu, S. Liu, Y. Zhang, J. Mater. Chem. A, 2014, 2, 15704-15716.

[15] P. Yin, T. Yao, Y. Wu, L. Zheng, Y. Lin, W. Liu, H. Ju, J. Zhu, X. Hong, Z. Deng, G. Zhou, S. Wei, Y. Li, Angew. Chem. Int. Ed., 2016, 55, 10800-10805.

[16] L. Li, J. He, Y. Wang, X. Lv, X. Gu, P. Dai, D. Liu, X. Zhao, J. Mater. Chem. A, 2019, 7, 1964-1988.

[17] S. Wang, X. Yan, K.-H. Wu, X. Chen, J.-M. Feng, P. Lu, H. Feng, H.-M. Cheng, J. Liang, S. X. Dou, Carbon, 2019, 144, 798-804.

[18] W. Li, C. Min, F. Tan, Z. Li, B. Zhang, R. Si, M. Xu, W. Liu, L. Zhou, Q. Wei, Y. Zhang, X. Yang, ACS Nano, 2019, 13, 3177-3187.

[19] H. Tan, J. Tang, J. Kim, Y. V. Kaneti, Y.-M. Kang, Y. Sugahara, Y. Yamauchi, J. Mater. Chem. A, 2019, 7, 1380-1393.

[20] N. T. Suen, S. F. Hung, Q. Quan, N. Zhang, Y. J. Xu, H. M. Chen, Chem. Soc. Rev., 2017, 46, 337-365.

[21] F. Lu, M. Zhou, Y. Zhou, X. Zeng, Small, 2017, 13, 1701931.

[22] N. Mamaca, E. Mayousse, S. Arrii-Clacens, T.W. Napporn, K. Servat, N. Guillet, K.B. Kokoh, Appl. Catal. B: Environm., 2012, 111-112, 376-380.

[23] T. Reier, M. Oezaslan, P. Strasser, ACS Catal., 2012, 2, 1765-177210.

[24] Z.-W. Gao, J.-Y. Liu, X.-M. Chen, X.-L. Zheng, J. Mao, H. Liu, T. Ma, L. Li, W.-C. Wang, X.-W. Du, Adv. Mater., 2019, 31, 1804769.

[25] B.-J. Kim, E. Fabbri, D. F. Abbott, X. Cheng, A. H. Clark, M. Nachtegaal, M. Borlaf, I. E. Castelli, T. Graule, T. J. Schmidt, J. Am. Chem. Soc., 2019, 141, 5231-5240.

[26] S. Sun, Y. Sun, Y. Zhou, S. Xi, X. Ren, B. Huang, H. Liao, L. P. Wang, Y. Du, Z. Xu, Angew. Chem. Int. Ed., 2019, 58, 6042-6047.

[27] C. Zhu, H. Li, S. Fu, D. Du, Y. Lin, Chem. Soc. Rev., 2016, 45, 517-531.

[28] M. Tahir, L. Pan, F. Idrees, X. Zhang, L. Wang, J.-J. Zou, Z. L. Wang, Nano Energy, 2017, 37, 136-157.

[29] W. T. Hong, M. Risch, K. A. Stoerzinger, A. Grimaud, J. Suntivich, Y. Shao-Horn, Energy Environ. Sci., 2015, 8, 1404-1427.

[30] J. O. Bockris, T. Otagawa, J. Phys. Chem. A, 1983, 87, 2960-2971.

[31] K. A. Stoerzinger, W. S. Choi, H. Jeen, H. N. Lee, Y. Shao-Horn, J. Phys. Chem. Lett., 2015, 6, 487-492.

[32] J. R. Petrie, V. R. Cooper, J. W. Freeland, T. L. Meyer, Z. Zhang, D. A. Lutterman, H. N. Lee, J. Am. Chem. Soc., 2016, 138, 2488-2491.

[33] S. F. Yuk, V. R. Cooper, Phys. Chem. Chem. Phys., 2019, 21, 4738-4745.

[34] S. K. Singh, K. Takeyasu, J. Nakamura, Adv. Mater., 2019, 31, 1804297.

[35] N. Jia, Q. Weng, Y. Shi, X. Shi, X. Chen, P. Chen, Z. An, Y. Chen, Nano Res., 2018, 11, 1905-1916.

[36] Z. Cui, S. Wang, Y. Zhang, M. Cao, J. Power Sources, 2014, 259, 138-144.

[37] L. Zhang, J. Niu, L. Dai, Z. Xia, Langmuir, 2012, 28, 7542-7550.

[38] K. Qu, Y. Zheng, Y. Jiao, X. Zhang, S. Dai, S.-Z. Qiao, Adv. Energy Mater., 2017, 7, 1602068.

[39] L. Yang, S. Jiang, Y. Zhao, L. Zhu, S. Chen, X. Wang, Q. Wu, J. Ma, Y. Ma, Z. Hu, Angew. Chem., Int. Ed., 2011, 50, 7132.

[40] J. P. Paraknowitsch, A. Thomas, Energy Environ. Sci., 2013, 6, 2839-2855.

[41] C. Zhang, N. Mahmood, H. Yin, F. Liu, Y. Hou, Adv. Mater., 2013, 25, 4932-4937.
[42] Y. Jia, L. Zhang, A. Du, G. Gao, J. Chen, X. Yan, C. L. Brown, X. Yao, Adv. Mater., 2016, 28, 9532-9538.

[43] C. Tang, H. F. Wang, X. Chen, B. Q. Li, T. Z. Hou, B. Zhang, Q. Zhang, M. M. Titirici, F. Wei, Adv. Mater., 2016, 28, 6845-6851.

[44] H. F. Wang, C. Tang, B, Wang, B. Q. Li, X. Cui, Q. Zhang, Energy Storage Mater., 2018, 15, 124-130.

[45] H. Osgood, S. V. Devaguptapu, H. Xu, J. Cho, G. Wu, Nano Today, 2016, 11, 601-625.

[46] Y. Zhu, W. Zhou, Z. Shao, Small, 2017,13, 1603793.

[47] J.-I. Jung, H. Y. Jeong, M. G. Kim, G. Nam, J. Park, J. Cho, Adv. Mater., 2015, 27, 266-271.

[48] H. Liu, K. Zhu, Y. Liu, W. Li, L. Cai, X. Zhu, M. Cheng, W. Yang, Electrochim. Acta, 2018, 279, 224-230.

[49] K. Zhu, H. Liu, X. Li, Q. Li, J. Wang, X. Zhu, W. Yang, Electrochim. Acta, 2017, 241, 433-439.

[50] K. Zhu, H. Liu, M. Li, X. Li, J. Wang, X. Zhu, W. Yang, J. Mater. Chem. A, 2017, 5, 7753-7758.

[51] Q. Wang, D. O'Hare, Chem. Rev., 2012, 112, 4124-4155.

[52] G. Fan, F. Li, D. G. Evans, X. Duan, Chem. Soc. Rev., 2014, 43 7040-7066.

[53] D. Zhou, Z. Cai, X. Lei, W. Tian, Y. Bi, Y. Jia, N. Han, T. Gao, Q. Zhang, Y. Kuang, J. Pan, X. Sun, X. Duan, Adv. Energy Mater., 2018, 8, 1701905.

[54] L. Wei, H. E. Karahan, S. Zhai, H. Liu, X. Chen, Z. Zhou, Y. Lei, Z. Liu, Y. Chen, Adv. Mater., 2017, 29, 1701410.

[55] X. Fan, F. Kong, A. Kong, A. Chen, Z. Zhou, Y. Shan, ACS Appl. Mater. Interfaces, 2017, 9, 32840-32850.

[56] T. Wang, G. Nam, Y. Jin, X. Wang, P. Ren, M. G. Kim, J. Liang, X. Wen, H. Jang, J. Han, Y. Huang, Q. Li, J. Cho, Adv. Mater., 2018, 30, e1800757.

[57] W.G. Hardin, D.A. Slanac, X. Wang, S. Dai, K.P. Johnston, K.J. Stevenson, J. Phys. Chem. Lett., 2013, 4, 1254-1259.

[58] M. Asnavandi, Y. Yin, Y. Li, C. Sun, C. Zhao, ACS Energy Lett., 2018, 3, 1515-1520

[59] K. Zhu, T. Wu, M. Li, R. Lu, X. Zhu, W. Yang, J. Mater. Chem. A, 2017, 5, 19836-19845.

[60] C.-F. Chen, G. King, R. M. Dickerson, P. A. Papin, S. Gupta, W. R. Kellogg, G. Wu, Nano Energy, 2015, 13, 423-432.

[61] J. Du, T. Zhang, F. Cheng, W. Chu, Z. Wu, J. Chen, Inorg. Chem., 2014, 53, 9106-9114.

[62] T. Ling, D. Y. Yan, Y. Jiao, H. Wang, Y. Zheng, X. Zheng, J. Mao, X. W. Du, Z. Hu, M. Jaroniec, S. Z. Qiao, Nat. Commun., 2016, 7, 12876.

[63] X. Liu, L. Wang, P. Yu, C. Tian, F. Sun, J. Ma, W. Li, H. Fu, Angew. Chem. Int. Ed., 2018, 57, 16166-16170.

[64] Z. Zhang, X. Wang, G. Cui, A. Zhang, X. Zhou, H. Xu, L. Gu, Nanoscale, 2014, 6, 3540-3544.

[65] T. Gao, Z. Jin, Y. Zhang, G. Tan, H. Yuan, D. Xiao, Electrochim. Acta, 2017, 258, 51-60.

[66] G.-L. Tian, Q. Zhang, B. Zhang, Y.-G. Jin, J.-Q. Huang, D. S. Su, F. Wei, Adv. Funct. Mater., 2014, 24, 5956-5961.

[67] R. Nandan, K. K. Nanda, J. Mater. Chem. A, 2017, 5, 16843-16853.

[68] G. L. Tian, M. Q. Zhao, D. Yu, X. Y. Kong, J. Q. Huang, Q. Zhang, F. Wei, Small, 2014, 10, 2251-2259.

[69] Y. J. Li, L. Cui, P. F. Da, K. W. Qiu, W. J. Qin, W. B. Hu, X. W. Du, K. Davey, T. Ling, S. Z. Qiao, Adv. Mater., 2018, 30, e1804653.

[70] Y. Guo, P. Yuan, J. Zhang, Y. Hu, I. S. Amiinu, X. Wang, J. Zhou, H. Xia, Z. Song, Q. Xu, S. Mu, ACS Nano, 2018, 12, 1894-1901.

[71] Y. Tang, R. Liu, S. Liu, B. Zheng, Y. Lu, R. Fu, D. Wu, M. Zhang, M. Rong, Carbon, 2019, 141, 704-711.

[72] K. Li, D. Guo, J. Kang, B. Wei, X. Zhang, Y. Chen, ACS Sustain. Chem. Eng., 2018, 6, 14641-14651. 
[73] X. Wang, L. Yu, B. Y. Guan, S. Song, X. W. D. Lou, Adv. Mater., 2018, 30, 1801211.

[74] W. Xiang, Y. Zhao, Z. Jiang, X. Li, H. Zhang, Y. Sun, Z. Ning, F. Du, P. Gao, J. Qian, K. Kato, M. Yamauchi, Y. Sun, J. Mater. Chem. A, 2018, 6, 23366-23377.

[75] S. A. Chala, M.-C. Tsai, W.-N. Su, K. B. Ibrahim, A. D. Duma, M.-H. Yeh, C.-Y. Wen, C.-H. Yu, T.-S. Chan, H. Dai, B.-J. Hwang, ACS Catal., 2018, 9, 117-129.

[76] Z. Wang, J. Ang, B. Zhang, Y. Zhang, X. Y. D. Ma, T. Yan, J. Liu, B. Che, Y. Huang, X. Lu, Appl. Catal. B, 2019, 254, 26-36.
[77] Z. Q. Liu, H. Cheng, N. Li, T. Y. Ma, Y. Z. Su, Adv. Mater., 2016, 28, 3777-3784.

[78] K. Zhu, M. Li, X. Li, X. Zhu, J. Wang, W. Yang, Chem. Commun., 2016, 52, 11803-11806.

[79] Y. Wu, X. Qiu, F. Liang, Q. Zhang, A. Koo, Y. Dai, Y. Lei, X. Sun, Appl. Catal. B, 2019, 241, 407-414.

[80] L. Dong, J. Su, Y. Wang, Y. Zhang, X. Chen, S. Zhou, J. Zang, Catal. Commun., 2019, 129, 105742.

[81] K. Zhu, X. Zhu, W. Yang, Angew. Chem. Int. Ed., 2019, 58, $1252-1265$.

\section{金属-空气电池中双功能电催化剂微纳结构设计 \\ 石 芳, ${ }^{\mathrm{a}, \mathrm{b}}$, 朱雪峰 ${ }^{\mathrm{a},}{ }^{*}$, 杨维慎 ${ }^{\mathrm{a}}$ \\ ${ }^{a}$ 中国科学院大连化学物理研究所, 催化基础国家重点实验室, 辽宁大连 116023 \\ ${ }^{\mathrm{b}}$ 中国科学院大学, 北京 100049}

摘要: 金属-空气二次电池在可再生电能的存储和转换方面具有广阔的应用前景. 在金属-空气二次电池的空气侧, 放电时 发生氧还原反应(ORR), 充电时发生氧析出反应(OER). 然而, ORR和OER反应的动力学过程缓慢, 因此限制了金属-空气二 次电池的实际应用. 因此, 发展高性能ORR 和OER电催化剂对金属-空气二次电池的发展尤为重要. 目前, 大多数的研究集 中在ORR或OER的单功能电催化剂上, 而关于双功能电催化剂的研究和综述相对较少. 两个反应均具有较高的过电位和 较缓慢的动力学过程, 而且充电过程的高电压会导致ORR催化剂失活, 反之亦然. 因此, 开发针对这两个反应均具有高活 性和高稳定性的双功能电催化剂极具挑战性. 近年来, 研究者对具有低成本和高性能双功能电催化剂进行了探索. 这些双 功能电催化剂包括碳基材料, 过渡金属材料和复合材料. 双功能电催化剂可以通过提高本征活性和表观活性两种策略来 提高其整体的活性. 其中, 本征活性与晶体结构和电子结构密切相关, 即可以通过调节晶体结构和电子结构来提高其本征 活性. 例如, 可以改变金属-氧键的强度、氧空位浓度等来调变电催化活性. 在碳基材料中掺杂杂原子可以改变碳的电荷密 度分布, 从而实现对电催化活性的提高. 此外, 其表观活性还可以通过改变形貌并利用协同作用来改善. 构建特殊微纳结 构是提高电催化活性的最常用策略之一. 在这种情况下, 电催化剂具有较高的比表面积, 大量的活性位点和良好的电子传 导性. 同时, 复合电催化剂组分之间在加速电催化过程中的协同作用不容忽视. 本文将聚焦双功能电催化剂的微纳结构设 计, 并简要讨论了纳米结构的精细调控和对反应机理的认识.

我们认为, 未来的工作应继续加强ORR和OER的新型双功能电催化剂的开发, 发展更多的合成方法对电催化剂的微纳 结构进行调变, 并对反应机理进行更深入的研究. 首先, 通过对结构的精细调变提高电催化剂的本征活性和表观活性. 此 外, 通过多种原位表征方法揭示反应机理, 这有助于电催化剂的设计和催化活性的进一步提升. 基于此, 开发出性能优异 的双功能电催化剂以加快用于存储和转换可再生能源的可充电金属-空气二次电池的商业化进程.

关键词: 氧还原反应; 氧析出反应; 可逆金属-空气电池; 双功能电催化剂; 微纳结构

收稿日期: 2019-07-24. 接受日期: 2019-09-23. 出版日期: 2020-03-05.

*通讯联系人. 电话: (0411)84379182; 传真: (0411)84379182; 电子邮箱: zhuxf@dicp.ac.cn

基金来源：国家自然科学基金(91545202, U1508203); 中国科学院战略重点研究项目(XDB17000000); 中国科学院青年创新促进 会、辽宁振兴人才工程(XLYC1807066).

本文的电子版全文由Elsevier出版社在ScienceDirect上出版(http://www.sciencedirect.com/science/journal/18722067). 